\title{
Periodic Trends behind the Stability of Metal Catalysts Supported on Graphene with Graphitic Nitrogen Defects
}

\author{
Vu Nguyen, Brian D. Etz, Svitlana Pylypenko, and Shubham Vyas* \\ Cite This: ACS Omega 2021, 6, 28215-28228 \\ Read Online
}

ABSTRACT: This study explored the fundamental chemical intricacies behind the interactions between metal catalysts and carbon supports with graphitic nitrogen defects. These interactions were probed by examining metal adsorption, specifically, the location of adsorption and the electronic structure of metal catalysts as the basis for the metal-support interactions (MSIs). A computational framework was developed, and a series of 12 transition metals was systematically studied over various graphene models with graphitic nitrogen defect(s). Different modeling approaches served to provide insights into previous MSI computational discrepancies, reviewing both truncated and periodic graphene models. The computational treatment affected the magnitudes of adsorption energies between the metals and

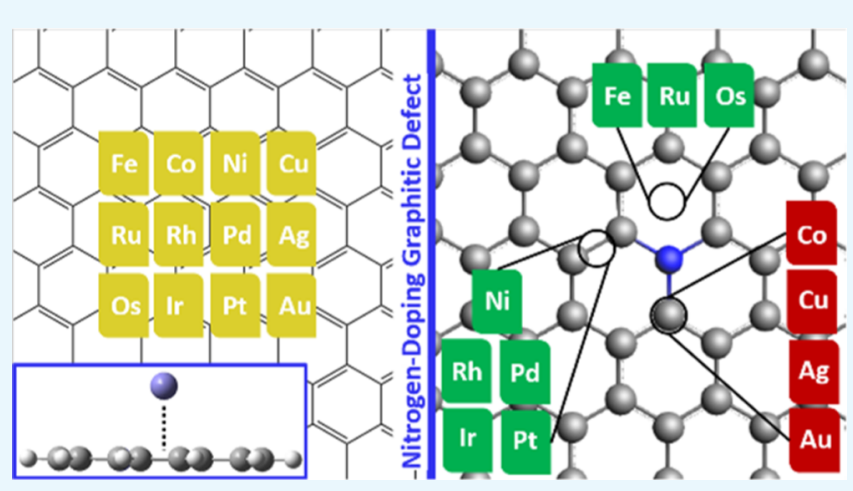
support; however, metals generally followed the same trends in their MSI. It was found that the addition of the nitrogen dopant improved the MSI by promoting electronic rearrangement from the metals' d- to s-orbitals for greater orbital overlap with the carbon support, shown with increased favorable adsorption. Furthermore, the study observed periodic trends that were adept descriptors of the MSI fundamental chemistries.

\section{INTRODUCTION}

Carbon materials are widely used across a multitude of applications due to high structural integrity and tunability with their comparative inexpensiveness. The spectrum of carbon materials, from single-layered graphene to structured carbon nanotubes to amorphous carbon, has been utilized as catalyst nanoparticle supports for a variety of applications due to the ability to tune their surface area, porosity, conductivity, and other characteristics. These properties contribute to the overall goal of a metal catalyst support by maximizing the usable nanoparticle's reactive surface through dispersion and immobilizing the catalysts for proceeding reactions through surface chemistries. $^{1-6}$ In polymer electrolyte membrane fuel cells (PEMFCs), carbon supports are used to disperse platinum nanoparticles to improve the electrochemical active surface. ${ }^{1,2,7-15}$ Even though this catalyst-support combination is a standard in the field, it is known to degrade over time under operable conditions through catalyst particle dissolution, particle coalescence, and detachment from the carbon support due to its corrosion, severely hindering its long-term performance. . $^{9-11,16-20}$

The inclusion of embedded nitrogen heteroatoms, as dopants, within the carbon lattice has shown to mitigate some degradation mechanisms through focused improvements in the metal-support interactions (MSI) and has allowed for novel material design that offers several advantages over undoped materials, all while preserving the low environmental and monetary costs of carbon materials. ${ }^{1,2,4,9,11,16,21,22}$ Nitrogen has been a promising choice, among other heteroatoms, as it creates electronic asymmetries, through several different functionalities or defects without major geometric disruptions, that allow for the manageable tuning of the MSI. ${ }^{5,7,9,21-23}$ Nitrogen-doped ( $\mathrm{N}$-doped) carbon materials have been experimentally shown to lessen metal nanoparticle dissolution when compared to undoped carbon materials, providing heightened catalyst stability and longevity. They also have presented other related benefits such as tuning the material's band gap for favored metal catalyst nanoparticle catalytic properties, promoting nanoparticle nucleation, and dispersing nanoparticles with greater uniformity. ${ }^{8,12,13,21,24-28}$ The benefits of $\mathrm{N}$-doped supports have been demonstrated using electron microscopy methods, rotating disk electrode measurements, and even in membrane electrode assemblies where it was shown that catalysts supported on $\mathrm{N}$-doped supports retain a greater current density after durability testing with nitrogen doping. ${ }^{23,25}$ Interestingly, this scale of molecular

Received: August 10, 2021

Accepted: September 28, 2021

Published: October 15, 2021

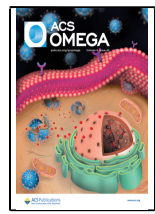


tuning draws parallels to active sites in enzymes where MSI is maintained for biological reactions through the enzymatic backbone similar to the dopants within the support. ${ }^{29}$ Beyond PEMFCs, other $\mathrm{N}$-doped carbons have been examined for applications in other types of fuel cells, as well as sensors, batteries, and hydrogen storage. There are two largely topical approaches in the synthesis of dopants within a carbon support, which contain methodologies that target certain dopant percentages or select for certain nitrogen functionalities over others. The first is "direct synthesis" where homogeneous precursors are made to react in situ to form the $\mathrm{N}$-doped carbon structure, while the second is "post-treatment" where nitrogen is implemented into pre-existing carbon structures. $^{23,30,31}$ There are various complementary characterization methods, such as X-ray photoelectron spectroscopy and scanning transmission electron microscopy, in accessing the structure and composition of the support, the MSI, and sites of interest. $^{32-34}$

Advantages of nitrogen doping with $\mathrm{Pt}$ and nonplatinum group metal catalysts have been demonstrated; however, they are usually shown with heterogeneous materials containing a multitude of nitrogen functionalities compared to an undoped reference for just one select catalyst. Moreover, experimental characterization techniques still require assistance in precisely identifying and correlating the fundamental interactions from doping that have been shown to improve the MSI, in terms of the electronic structure and contributions to catalyst stability. Along with fully elucidating the chemistries behind the MSI, the call to action is to establish the optimal functionalities for each catalyst over a range of possible metals. Direct systematic comparison between metals' underlying interactions with a [doped] support is lacking, and furthermore, presented metal speciation and nucleation may not directly translate into stability when in applicable settings. ${ }^{35-38}$

Theoretical work, such as density functional theory (DFT), can be extremely useful for improving the understanding of $\mathrm{N}$ doped materials. DFT has helped to assist in synthetic variability in determining core-level shifts to elucidate X-ray photoelectron spectroscopy binding energy spectra/experimental signatures. ${ }^{39-41}$ DFT has also been used to directly study the electronic nature of the support and the MSI through defining orbital interactions and band gaps between the metal and support along with calculating relevant MSI metrics, such as adsorption energy of the metal, ripening energy of the metal, and defect formation energies. ${ }^{7,28,42-44}$ While these measures can be correlated and extrapolated to physical systems, DFT has also been utilized to explore more macroscopic properties such as predicting affinities for electrochemical absorbates and relative stabilities of nitrogen dopants and their morphologies within the carbon material. ${ }^{36,45-49}$ Pyridinic clusters (of three or four pyridinic nitrogen around a vacancy created by missing/defective carbons) have been largely investigated along with graphitic and pyrrolic defects across metals involving $\mathrm{Pt}, \mathrm{Pd}, \mathrm{Fe}, \mathrm{Co}$, and $\mathrm{Ni}$ with even inclusions of $\mathrm{Ru}$ and $\mathrm{Mn}$. $12,43,50-54$

Despite the aforesaid computational studies, many of them retain a similar limitation where only one type of the metal catalyst in tandem with one type of defect is investigated, usually upon a graphene representation. While a handful does serve to match an experimental system and does share commonplace methods within the field, such as the utilization of the Perdew-Burke-Ernzerhof (PBE) functional, differences in some chosen computational parameters make a direct comparison speculative and energetic discrepancies apparent. $7,26,31,45,55,56$ For example, given pristine graphene, unit cell sizing for planewave DFT methods may be insignificant; however, the addition of a metal atom(s) and nitrogen defect(s) introduces possible artificial interactions between periodic images, similar to periodically charged point defects that may not surpass the "dilute limit". ${ }^{57-59}$ Calle-Vallejo et al. used two similarly doped unit cells that differed in length by a row of carbon atoms to highlight morphological differences that propagated into thermodynamic differences of oxygen reduction reaction (ORR) activity between the two cells. ${ }^{60}$ Tangentially, representative truncated graphene-like models have also been used to explore similar properties, but their lack of periodicity and the nuances associated must also be considered. $^{7,22,23,27,48,54,61-65}$ It is essential to then, along with furthering systematic studies of various metals and defects, to utilize comparable parameters or gauge methodological discrepancies to examine the sought-after principal interactions.

The goal of this work is to conduct a critical evaluation of the computational models used for the investigation of MSI and systematically study any periodic trends in interactions with $\mathrm{N}$-doped supports using different metals, including noble and non-noble metals from different groups and periods across the periodic table. Different models of $\mathrm{N}$-doped graphene over two major computational approaches are evaluated to establish a suitable computational framework and parameter space to probe interactions between metal catalysts and $\mathrm{N}$-doped carbon supports. For periodic models, the study comments on the choice of the unit cell in representing $\mathrm{N}$-doped graphene and the treatment of spin in truncated models resulting from the introduction of a single graphitic defect. Insights into the material's edge are found within truncated models, another predominantly relevant physical factor as it has been suggested that the edge graphitic defects have higher ORR activity. ${ }^{48}$ Furthermore, a comparison between these two types of modeling approaches indicates the significance of computational periodicity. In this paper, we present a systematic DFT study that includes 12 transition metals with the carbon support containing a graphitic nitrogen defect to provide a foundation in understanding the principal interactions between the metal and support through metal adsorption and the resulting electronic distribution. It was found that periodic relations are adept descriptors in starting to define the MSI. This work creates the groundwork for further investigations into studies of catalyst stability when supported on graphitic and other types of nitrogen defects.

\section{RESULTS AND DISCUSSION}

2.1. Truncated Models. Both the modes of adsorption (MOA) and energy of adsorption were evaluated to (1) identify appropriate treatment for the $\mathrm{N}$-doped carbon support, (2) understand the fundamental interactions between the support and the metal catalyst, and (3) delineate any periodic trends that exist in the metal-support interactions for the chosen metals. MOA refers to the location in which the metal ultimately optimizes over the graphene sheet, denoted with the same naming convention for metal-starting locations (Figure 2). MOAs that were not directly over an atom or in the middle of holes are labeled as CC since they are nondiscrete between carbon atoms, unless they are between the nitrogen atom and an adjacent carbon atom in which case they are labeled as bonded with $\mathrm{N}$. By associating this spatial evaluation 


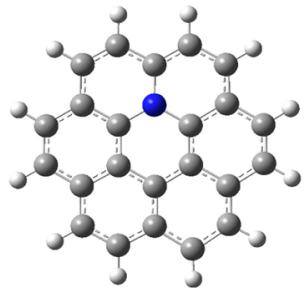

b)

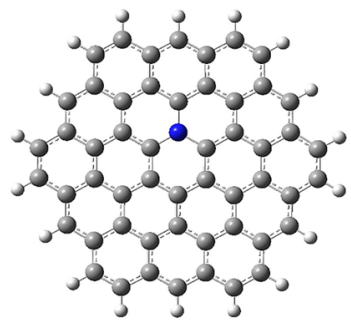

Figure 1. Representation of the truncated graphene models: (a) twoshell truncated model with graphitic defect and (b) three-shell truncated model with graphitic defect. The gray, blue, and white spheres are carbon, nitrogen, and hydrogen atoms, respectively, for the above representations. The control models represent undoped graphene in which the nitrogen atom is replaced with a carbon atom in the above representations.

with $\mathbf{E}_{\text {ads }}$, the fundamental interactions of the metal with the support were investigated relative to the addition of the dopant. This may also provide insights into initial metal nucleation sites upon the support. Thus, the following section covers these two main metrics, and later sections explore edge effects with the three-shell model and systematic trends.

2.1.1. Two-Shell Model: Adsorption Energies/Modes of Adsorption and Model Development. The $\mathbf{E}_{\text {ads }}$ and MOA were found for the 12 metals with the three two-shell truncated graphene models: undoped (control), doublet ( $\mathrm{N}$-doped), and singlet (N-doped). Even though four discrete starting locations were considered for metal catalysts, the geometry generally converged to one MOA type with some exceptions (see Figure S3). The most favorable $\mathbf{E}_{\text {ads }}$ along with its corresponding mode of adsorption was considered in the following discussion. Table 1 presents the most favorable $\mathbf{E}_{\text {ads }}$ with the corresponding mode of adsorption for all the metals over the three different supports calculated at all levels of theories.

The undoped graphene model was compared to both singlet and doublet $\mathrm{N}$-doped models to investigate how graphitic defects affect the adsorption energies and MOA of the metal. The $\mathbf{E}_{\text {ads }}$ for each metal generally became more favorable when adding the graphitic nitrogen defect regardless of the singlet or doublet models. Across all three models for almost all the metals considered, the magnitudes of adsorption energies exceed $0.5 \mathrm{eV}$, which is the threshold energy for atomic migration at room temperature, implying that the $\mathbf{E}_{\text {ads }}$ from these interactions is likely to withstand particle mitigation at room temperature, thereby imparting more stability. ${ }^{64}$ The inner MOA and the edge MOA also generally stay the same when comparing the graphene control and doped graphene with the major difference being their respective distances from the defect and the edge. This indicates that the nature of electronic communication between the metal and carbon support remains unchanged, even though this communication was strengthened upon the introduction of the graphitic nitrogen defect. It was also found that most metals across all systems optimized to a single type of MOA, even though the starting geometric arrangement is different.

Notably, it is also found that most metals do not directly interact with the nitrogen atom, similar to what has been shown for $\mathrm{Pt}$ in previous investigations. ${ }^{7,67}$ In the doublet doped model, there are some MOAs directly interacting with nitrogen, but most of these interactions are over the nitrogencarbon bond rather than over the nitrogen atom. Only in the case of Co was direct interaction with nitrogen observed across all functionals, even though with mostly unfavorable adsorption energies. For the rest of the metals, direct interaction of metals with nitrogen atoms was seen only for some functionals. In the singlet doped model, direct interaction of metals with the doped nitrogen atom was rare. Only Ir interacts with the edge nitrogen-carbon bond, but this interaction may be dictated by edge effects rather than the defect nitrogen as this was not its most favorable MOA.

This discrepancy suggests that the direct nitrogen interaction is an artifact of the doublet treatment of the doped carbon support. The lone electron on nitrogen promotes increased interaction between the metal and nitrogen as shown with higher magnitudes of $\mathbf{E}_{\mathbf{a d s}}$ in the doublet. Additionally, there were more edge MOAs found for the doublet model when compared to those for the singlet treatment. This again may be a relic of the doublet treatment where now conversely the lone electron does not favorably pair up with the metal at the nitrogen but rather is stabilized by distributing electron density outward to the edge locations. The opposite is observed in the singlet model as it has the most internal MOA. These sites in the singlet treatment also had more favorable $\mathbf{E}_{\text {ads }}$ than the equivalent mode on the doublet doped support (except for the group 11 metals). Even though there is no direct nitrogen interaction, the graphitic
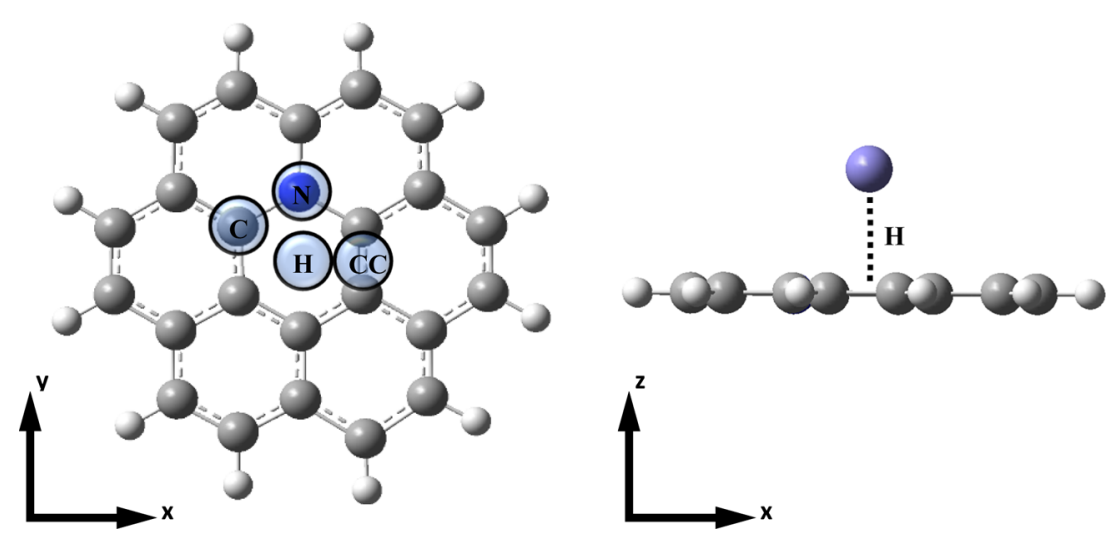

Figure 2. Annotated starting locations of the metal atom over the two-shell with respect to the graphitic defect. The labels represent the following positions: over the hole directly between the surrounding carbon atoms and nitrogen atoms $(\mathrm{H})$, over the nitrogen of the graphitic defect $(\mathrm{N}$, not present in undoped controls), over the inner carbon atom adjacent to nitrogen (C), and over the inner carbon-carbon bond adjacent to the nitrogen-carbon bond (CC). 
Table 1. Most Favorable (as Defined by a Greater Negative Value) Adsorption Energies ( $E_{\text {ads }}$ in eV) Calculated Using the TwoShell Graphitic Defect Truncated Graphene Models with the Four DFT Functionals (B3LYP, $\omega$ B97xd, PBE1PBE, and HSE) ${ }^{a}$

\begin{tabular}{|c|c|c|c|c|c|c|c|c|}
\hline \multirow[b]{2}{*}{ metal } & \multicolumn{2}{|c|}{ B3LYP } & \multicolumn{2}{|c|}{$\omega \mathrm{B} 97 \mathrm{xd}$} & \multicolumn{2}{|c|}{ PBE1PBE } & \multicolumn{2}{|c|}{ HSE } \\
\hline & MOA & $\mathbf{E}_{\text {ads }}$ & MOA & $\mathbf{E}_{\text {ads }}$ & MOA & $\mathbf{E}_{\text {ads }}$ & MOA & $\mathbf{E}_{\text {ads }}$ \\
\hline \multicolumn{9}{|c|}{ undoped control } \\
\hline $\mathrm{Fe}$ & $\mathrm{H}(\mathrm{H})$ & $-0.91(-1.60)$ & $(\mathrm{H})$ & $(-1.96)$ & $\mathrm{H}(\mathrm{H})$ & $-1.58(-2.31)$ & $(\mathrm{H})$ & $(-2.26)$ \\
\hline $\mathrm{Ru}$ & $\mathrm{H}$ & -1.87 & $\mathrm{H}(\mathrm{H})$ & $-0.09(-3.88)$ & $\mathrm{H}(\mathrm{H})$ & $-2.67(-5.16)$ & $\mathrm{H}$ & -2.62 \\
\hline Os & $\mathrm{H}$ & -1.71 & $\mathrm{CC}$ & 0.11 & $\mathrm{H}(\mathrm{H})$ & $-2.54(-4.77)$ & $\mathrm{H}$ & -2.65 \\
\hline Co & $\mathrm{H}(\mathrm{CC})$ & $0.08(-0.48)$ & $\mathrm{CC}$ & -1.13 & $\mathrm{CC}$ & -0.06 & $(\mathrm{CC})$ & $(-0.21)$ \\
\hline $\mathrm{Rh}$ & $\mathrm{CC}$ & -0.95 & $\mathrm{CC}$ & -1.23 & $(\mathrm{CC})$ & $(-2.17)$ & $\mathrm{CC}$ & -1.31 \\
\hline $\mathrm{Ir}$ & $\mathrm{H}(\mathrm{CC})$ & $-0.95(-2.18)$ & $(\mathrm{CC})$ & $(-2.67)$ & $\mathrm{CC}(\mathrm{CC})$ & $-1.36(-2.67)$ & $\mathrm{CC}$ & -2.40 \\
\hline $\mathrm{Ni}$ & $\mathrm{CC}(\mathrm{CC})$ & $-1.29(-1.41)$ & CC (CC) & $-1.91(-2.08)$ & $\mathrm{H}(\mathrm{CC})$ & $-1.78(-1.83)$ & $\mathrm{H}$ & -1.72 \\
\hline $\mathrm{Pd}$ & $\mathrm{CC}(\mathrm{CC})$ & $-0.54(-1.18)$ & $\mathrm{CC}(\mathrm{CC})$ & $-0.80(-1.36)$ & $\mathrm{CC}(\mathrm{CC})$ & $-0.82(-1.46)$ & $\mathrm{CC}(\mathrm{CC})$ & $-0.84(-1.46)$ \\
\hline $\mathrm{Pt}$ & $\mathrm{CC}$ & -1.40 & CC (CC) & $-1.68(-1.95)$ & $\mathrm{CC}(\mathrm{CC})$ & $-1.79(-2.01)$ & $\mathrm{CC}$ & -1.78 \\
\hline $\mathrm{Cu}$ & $C(C)$ & $0.01(-0.03)$ & $\mathrm{C}$ & -0.19 & $\mathrm{C}$ & -0.02 & $\mathrm{C}$ & -1.03 \\
\hline $\mathrm{Ag}$ & $\mathrm{CC}$ & 0.01 & $\mathrm{C}$ & -0.23 & $\mathrm{C}$ & -0.02 & $\mathrm{C}$ & -1.03 \\
\hline $\mathrm{Au}$ & \multicolumn{7}{|c|}{ doublet doped } & -1.05 \\
\hline $\mathrm{Fe}$ & $(\mathrm{CC})$ & $(-2.44)$ & $(\mathrm{H})$ & $(-2.42)$ & $\mathrm{H}(\mathrm{CC})$ & $-3.35(-2.95)$ & $\mathrm{H}(\mathrm{CC})$ & $-3.28(-3.53)$ \\
\hline $\mathrm{Ru}$ & $\mathrm{CC}(\mathrm{N})$ & $-3.61(-3.22)$ & $(\mathrm{H})$ & $(-3.84)$ & $\mathrm{H}(\mathrm{CC})$ & $-3.23(-3.61)$ & $\mathrm{H}$ & -3.20 \\
\hline Os & $\mathrm{H}$ & -2.68 & $\mathrm{CC}$ & -5.67 & $\mathrm{H}(\mathrm{N})$ & $-4.11(-3.79)$ & $\mathrm{N}$ & -3.88 \\
\hline Co & $\mathrm{N}(\mathrm{N})$ & $0.33(0.38)$ & $\mathrm{CC}(\mathrm{N})$ & $-0.06(-2.63)$ & $\mathrm{N}(\mathrm{N})$ & $0.66(0.39)$ & $\mathrm{CC}(\mathrm{N})$ & $0.22(0.37)$ \\
\hline $\mathrm{Rh}$ & $\mathrm{CC}(\mathrm{N})$ & $-2.01(-1.67)$ & $(\mathrm{CC})$ & $(-2.84)$ & $\mathrm{CC}(\mathrm{CC})$ & $-2.50(-2.96)$ & $\mathrm{CC}(\mathrm{CC})$ & $-2.33(-2.92)$ \\
\hline $\mathrm{Ir}$ & $(\mathrm{CC})$ & $(-3.00)$ & $\mathrm{CC}(\mathrm{CC})$ & $-3.71(-4.43)$ & $\mathrm{CC}(\mathrm{N})$ & $-3.92(-3.10)$ & $\mathrm{CC}(\mathrm{N})$ & $-3.87(-3.07)$ \\
\hline $\mathrm{Ni}$ & $\mathrm{CC}(\mathrm{CC})$ & $-1.69(-1.80)$ & $\mathrm{CC}(\mathrm{CC})$ & $-2.14(-2.36)$ & $\mathrm{CC}(\mathrm{CC})$ & $-2.05(-2.40)$ & $\mathrm{C}$ & -2.69 \\
\hline $\mathrm{Pd}$ & $\mathrm{CC}(\mathrm{CC})$ & $-0.76(-1.10)$ & $\mathrm{CC}(\mathrm{CC})$ & $-0.89(-1.00)$ & $\mathrm{CC}(\mathrm{CC})$ & $-0.99(-1.07)$ & $\mathrm{CC}(\mathrm{CC})$ & $-1.02(-1.36)$ \\
\hline $\mathrm{Pt}$ & CC (CC) & $-0.54(-2.46)$ & CC (CC) & $-2.44(-2.61)$ & $\mathrm{N}(\mathrm{CC})$ & $-1.40(-2.79)$ & $\mathrm{CC}$ & -2.67 \\
\hline $\mathrm{Cu}$ & $\mathrm{C}(\mathrm{C})$ & $-0.96(-1.00)$ & $\mathrm{C}$ & $-1.29(-1.39)$ & $\mathrm{C}(\mathrm{C})$ & $-1.06(-1.10)$ & $\mathrm{C}$ & -1.07 \\
\hline $\mathrm{Ag}$ & (C) & $(-0.54)$ & (C) & $(-0.95)$ & $\mathrm{C}(\mathrm{C})$ & $-0.55(-0.68)$ & $\mathrm{C}(\mathrm{C})$ & $-0.54(-0.68)$ \\
\hline \multicolumn{9}{|c|}{ singlet doped } \\
\hline $\mathrm{Fe}$ & $\mathrm{H}$ & -1.66 & $\mathrm{H}$ & -2.11 & $\mathrm{H}$ & -1.85 & (C) & $(-3.91)$ \\
\hline $\mathrm{Ru}$ & $(\mathrm{H})$ & $(-3.21)$ & $\mathrm{H}$ & -4.01 & $\mathrm{H}(\mathrm{H})$ & $-4.61(-5.10)$ & $\mathrm{H}$ & -4.21 \\
\hline Os & $\mathrm{CC}(\mathrm{CC})$ & $-3.54(-3.41)$ & $\mathrm{CC}$ & -3.42 & $\mathrm{CC}$ & -3.42 & $(\mathrm{H})$ & $(-5.02)$ \\
\hline Co & $(\mathrm{H})$ & $(-0.65)$ & $\mathrm{CC}$ & -2.73 & (C) & $(-1.82)$ & $\mathrm{CC}(\mathrm{H})$ & $0.46(-1.78)$ \\
\hline $\mathrm{Rh}$ & $\mathrm{CC}$ & -1.88 & $\mathrm{CC}$ & -2.13 & $\mathrm{CC}$ & -2.26 & $\mathrm{CC}$ & -2.24 \\
\hline $\mathrm{Ir}$ & $\mathrm{CC}(\mathrm{N})$ & $-3.28(-2.41)$ & $\mathrm{CC}$ & -3.69 & $\mathrm{CC}(\mathrm{N})$ & $-3.79(-2.96)$ & $(\mathrm{N})$ & $(-2.90)$ \\
\hline $\mathrm{Ni}$ & $\mathrm{CC}$ & -2.10 & $\mathrm{CC}(\mathrm{CC})$ & $-2.80(-2.74)$ & $\mathrm{CC}$ & -2.44 & $\mathrm{CC}$ & -2.85 \\
\hline $\mathrm{Pd}$ & $\mathrm{CC}(\mathrm{CC})$ & $-1.07(-1.01)$ & $\mathrm{CC}$ & -1.35 & $\mathrm{CC}(\mathrm{C})$ & $-1.36(-1.29)$ & $\mathrm{CC}(\mathrm{CC})$ & $-1.37(-1.38)$ \\
\hline $\mathrm{Pt}$ & $\mathrm{CC}$ & -2.66 & $\mathrm{CC}(\mathrm{CC})$ & $-3.00(-3.31)$ & $\mathrm{CC}$ & -3.05 & $\mathrm{CC}$ & -3.03 \\
\hline $\mathrm{Cu}$ & $\mathrm{C}$ & -0.03 & $\mathrm{C}$ & -0.32 & $\mathrm{C}(\mathrm{C})$ & $-0.19(-1.66)$ & $\mathrm{C}(\mathrm{C})$ & $-0.21(-1.61)$ \\
\hline $\mathrm{Ag}$ & $\mathrm{CC}$ & 0.00 & $\mathrm{C}$ & -0.26 & $\mathrm{C}(\mathrm{C})$ & $-0.05(-1.18)$ & $\mathrm{C}(\mathrm{C})$ & $-0.05(-1.14)$ \\
\hline $\mathrm{Au}$ & $\mathrm{CC}$ & -0.26 & $\mathrm{C}$ & -0.66 & $\mathrm{C}$ & -0.52 & $\mathrm{C}$ & -0.54 \\
\hline
\end{tabular}

${ }^{a}$ Notation for MOA is shown in Figure 2. The lettering and values contained within parentheses represent edge-equivalent MOA with the corresponding $\mathbf{E}_{\text {ads }}$.

nitrogen draws electron density from the adjacent carbons, impacting the resulting MSI. Furthermore, when a dopant was present, the optimized MOA tended to not be located at the edge but closer to the defect. Conversely, without the dopant, the MOA tended to be more at the edge, indicating that the defect does promote favorable MOA within its vicinity. Moreover, previous experimental results and the proposed doped graphene structure suggest that the doublet treatment is not appropriate. ${ }^{25,35,81}$ As a result, the singlet treatment is a more representative model and will be the focus of discussion moving forward. With the singlet treatment of the truncated model, it should be noted that the model is asymmetrical; however, there appears to be no bias in the metals optimizing toward or away from the $\mathrm{sp}^{3}$ edge carbon (see Figure $\mathrm{S} 1$ ).

The $\mathbf{E}_{\text {ads }}$ calculated with the B3LYP functional tended to be more conservative, as shown in Table 1 , as compared to the other functionals, which were all similar in magnitude. Noticeably, results with the $\omega \mathrm{B} 97 \mathrm{xd}$ functional showed the least amount of edge MOA. Long-range corrections in the $\omega \mathrm{B} 97 \mathrm{xd}$ functional most likely caused the metal to be stabilized around the starting internal positions rather than optimizing to edge MOA. However, $\omega$ B97xd had no favorable (around $0 \mathrm{eV}$ ) internal MOA for group 8 metals with the undoped control support. This differs significantly for group 8 metals as compared to the other functionals where their $\mathbf{E}_{\text {ads }}$ values were about $2-3 \mathrm{eV}$, which also implies that doping would increase these metal's MOA by 3-4 eV. It was observed that the PBE1PBE functional matched the best with the benchmark, HSE functional, when comparing the adsorption magnitudes and MOA, even mirroring exceptions. The expensive treatment of long- and short-range interactions did not appear to have a significant effect. It was also noticed that 
Co was the most functional-dependent as there was only one nonedge favorable MOA, while the rest was unfavorable MOA. Nevertheless, Co did have a favorable edge MOA, even though the type of MOA differed between functionals. This could imply that Co does not have any favorable adsorption mode with the support, outside of stabilization found at the edge.

It should be prefaced that there are exceptions within the trends; however, these exceptions are derived from two computational factors. First, the exceptions are dependent on the computational method. Second, regarding the metal's MOA, the metal's optimized position was sometimes nondiscrete, and the judgment outlined in the methods may not be reflective of the adsorption's true nature. Moreover, optimized positions near the edge of the graphene model were identified and are discussed further (vide infra).

With these observations, the PBE1PBE functional was chosen moving forward for all further analysis. Figure 4

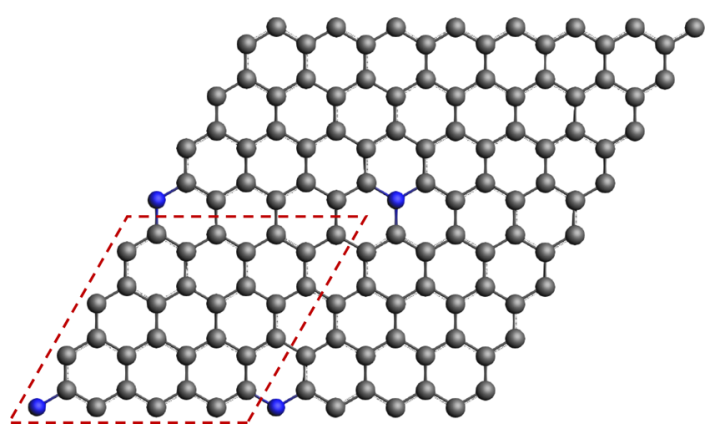

Figure 3. $8 \times 8$ unit cell and the $4 \times 4$ unit cells' sizing (outlined in the red dashed box) is presented. Two $4 \times 4$ unit cells were prepared; the first contains the same number of graphitic defects as the $8 \times 8$ unit cell (four total) and equally spaced (referred to as $4 \times 4$ unit cell A), and the second contains the same density of graphitic defects (one total, referred to as $4 \times 4$ unit cell B). These $4 \times 4$ unit cells are shown in Figure S2. The dimensions $n \times n$ are positive integers determined by numbering the outer most carbons on one edge across.

presents the results from the two-shell model with the PBE1PBE functional, for which the periodic trends will be discussed in much greater details (vide infra, Section 3.1.3). From Figure 4, it can be concluded that the graphitic defect generally increases the magnitude of $\mathbf{E}_{\text {ads }}$ in both doublet and singlet cases from the control while maintaining similar MOA. It also highlights the reasons why the singlet treatment was chosen over the doublet one. To further confirm if the observed edge MOAs are representative or an artifact of the two-shell model, the study expanded to examine a three-shell model, as discussed in the next section.

2.1.2. Three-Shell Truncated Model. A possible pitfall of the two-shell model is the limited size of the graphene surface that could bias the MOA to be at the edge. It is evident from Table 1 that the metals' MOA remains largely unchanged when the metal is optimized to an edge location, implying that the interactions between the metal and surface are not affected by the edge. Additionally, the difference in $\mathbf{E}_{\text {ads }}$ between the edge MOA and nonedge MOA was relatively unchanged, about 0.1 $\mathrm{eV}$. Nevertheless, a three-shell model was used to further investigate this phenomenon. The extra "shell" of separation between the metal and defect to the edge allowed for the study to eliminate any significant role the edge in the two-shell model might contribute to $\mathbf{E}_{\text {ads }}$ and MOA. Given the findings from the two-shell model, only PBE1PBE was used on a singlet
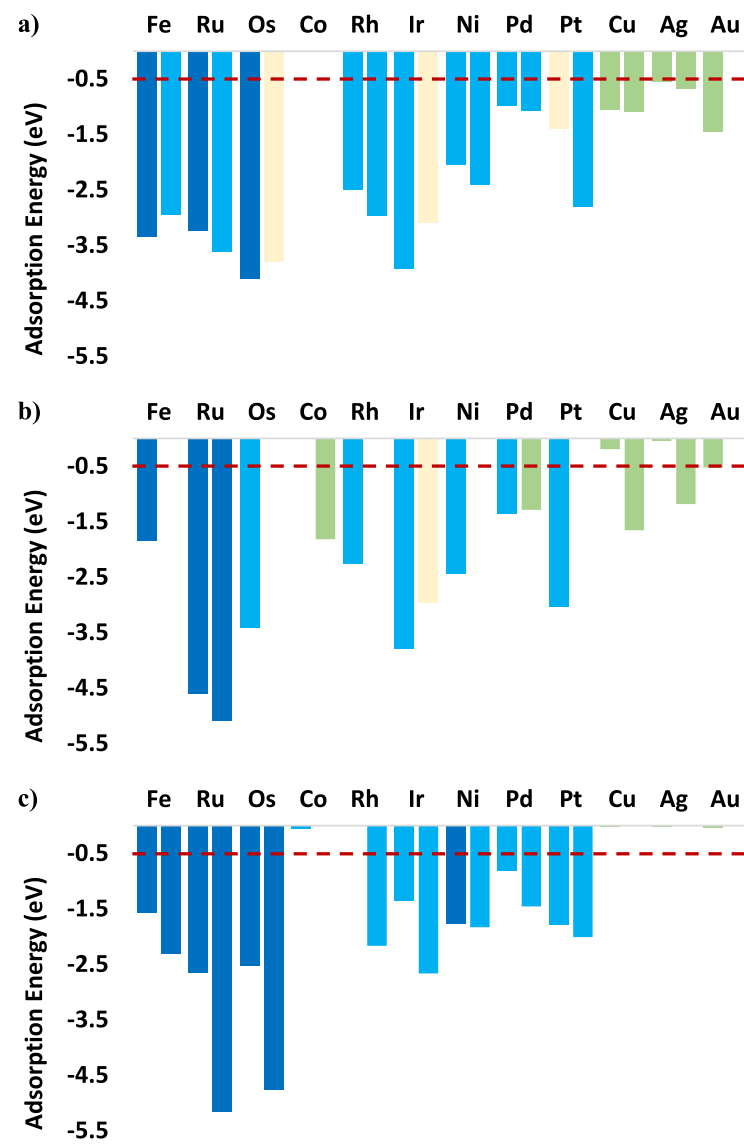

Figure 4. $\mathrm{E}_{\mathrm{ads}}$ and MOA from Figure 3 of the PBE1PBE functional for the (a) doublet, (b) singlet, and (c) control two-shell supports. The two bars for each metal represent the nonedge MOA (left bar) and the edge MOA (right bar), given that the metal has a nonedge/edge MOA. The different colors of the bar represent the MOA: dark blue is over $\mathrm{H}$, light blue is over $\mathrm{CC}$, lighter green is over $\mathrm{C}$, and lightest yellow is over $\mathrm{N}$. The red line indicates the $-0.5 \mathrm{eV}$ threshold for particle migration at room temperature.

version of the three-shell system with solely $H$ as the metalstarting location.

Figure 5 shows the results from the three-shell model compared with the two-shell model. The two truncated models generally share the same MOA among all 12 metals except for Os, Co, and Rh. The Os over the doped and undoped support and Co over the doped support did not optimize when using the three-shell model. For Rh, MOA on the undoped support was different when compared to that of the two-shell model. In general, $\mathbf{E}_{\text {ads }}$ of metals over the undoped support remained largely unchanged when comparing two-shell models to threeshell models (the largest difference of about $0.4 \mathrm{eV}$ not including the above exceptions). The difference in $\mathbf{E}_{\text {ads }}$ between the two models was observed in the doped versions of the models where $\mathrm{Ru}, \mathrm{Rh}$, group 10 , and group 11 metals had more favorable $\mathbf{E}_{\text {ads }}$ in the two-shell when compared to the three-shell models.

Pt is one of the most studied metals regarding interactions with nitrogen dopants; therefore, it is important to examine our observations considering the past literature. Between the two models, the doped two-shell model predicted a $1.26 \mathrm{eV}$ increase in magnitude, while the three-shell predicted $0.13 \mathrm{eV}$ increase. The much greater reported $\mathbf{E}_{\text {ads }}$ for the two-shell system might stem from a nuance discussed in Section 3.1.3. 
a)
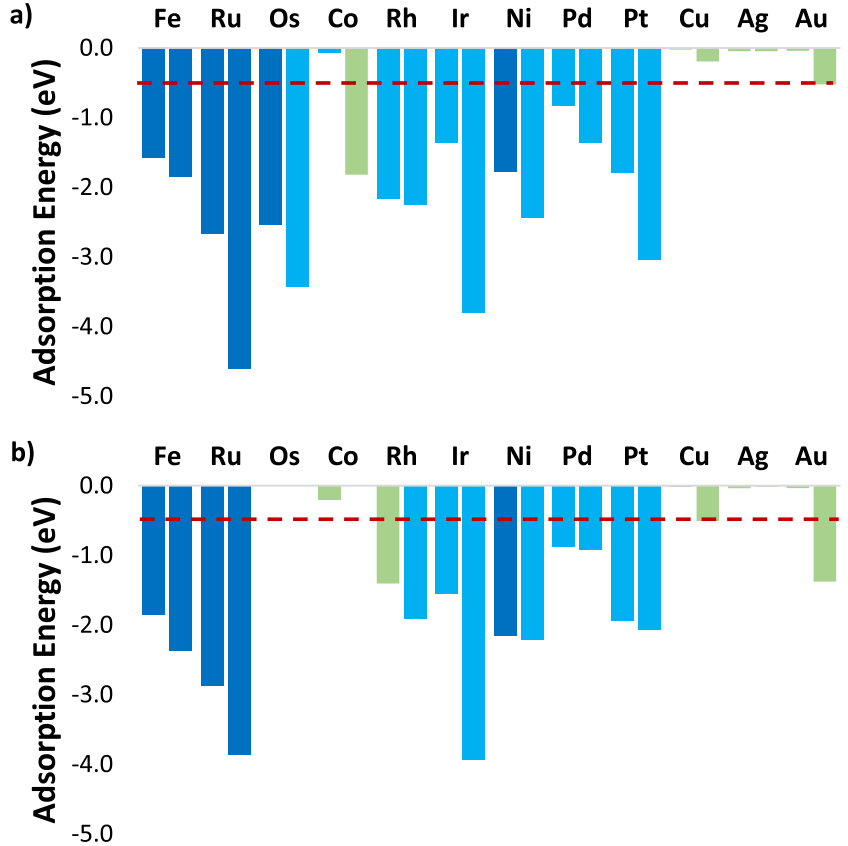

Figure 5. Adsorption energies and MOA of the metals with the support of the truncated models obtained at the PBE1PBE/6$31+G(d)$ level of theory: (a) two-shell truncated model and (b) threeshell truncated model. Each metal has two bars where the left one refers to the undoped support and the right one refers to the doped equivalent. Regarding the two-shell model, all data points shown are nonedge MOA with the corresponding $\mathbf{E}_{\text {ads }}$ unless the metal did not have a nonedge MOA, in which case the results from edge MOA are shown. Any omitted points are a result of not being able to obtain a stationary point for the metal with the three-shell model. The different colors of the bar represent the MOA: dark blue is over $\mathrm{H}$, light blue is over CC, and green is over $\mathrm{C}$. The red line indicates the $-0.5 \mathrm{eV}$ threshold for particle migration at room temperature.

Muhich et al. examined nitrogen doping on graphene with respect to a $\mathrm{Pt}$ atom and observed that the $\mathbf{E}_{\text {ads }}$ increased by $0.4 \mathrm{eV}$ with the addition of a sole graphitic defect (with the same MOA as $\mathrm{Pt}$ in this study). However in the same study, it was seen that $\mathbf{E}_{\mathrm{ads}}$ increased by $1.4 \mathrm{eV}$ with vacancies of three pyridinic defects. ${ }^{7}$ In the three-shell model, it could be implied that the benefits from nitrogen doping do not reside solely on the graphitic defect and that $\mathrm{Fe}, \mathrm{Ru}$, and $\mathrm{Ir}$ have stronger interactions with graphitic nitrogen defects. While the $\mathbf{E}_{\text {ads }}$ between the two models differs, the nature of the interaction between the metal and support is the same as the MOA that remains consistent. The three-shell model offers a more physical portrayal of graphene; however, since the MOA and trends are preserved, the two-shell model can be utilized for efficient screening before alluding to larger representative models.

2.1.3. Systematic Trends. The nature of the increased electronic interactions due to doping of the graphene support appears to be group-dependent, confirming the presence of a periodic dependence on the fundamental interactions. Based on the MOA in the two-shell model, there are group trends. For example, group 10 metals generally had only CC MOA, while group 11 metals preferred to be on top of a $\mathrm{C}$ atom, with $\mathrm{Au}$ alternating between $\mathrm{C}$ and CC MOA. For group 9 metals, $\mathrm{Rh}$ and Ir optimized over the CC position with Ir further interacting with the $\mathrm{N}-\mathrm{C}$ edge bond. Co only had favorable edge MOA of $\mathrm{C}$. In group 8, Os varied between $\mathrm{H}$ and $\mathrm{CC}$, while $\mathrm{Fe}$ and $\mathrm{Ru}$ optimized primarily over the $\mathrm{H}$ position.

It was observed that the metals that had a relatively greater $\mathbf{E}_{\text {ads }}$ also caused a larger conformational change in the support deviating from a planar geometry. It could be hypothesized that there exists a correlation between the $\mathbf{E}_{\text {ads }}$ and the degree of the conformational change in the support structure. This conformational change appeared to be only experienced with the metals on the $\mathrm{N}$-doped models and not on the undoped control. In the undoped models, the carbon atoms interacting with the metal were, at most, slightly raised above the graphene plane; in the doped models, the conformational change is much more drastic, as exemplified in Figure 6.

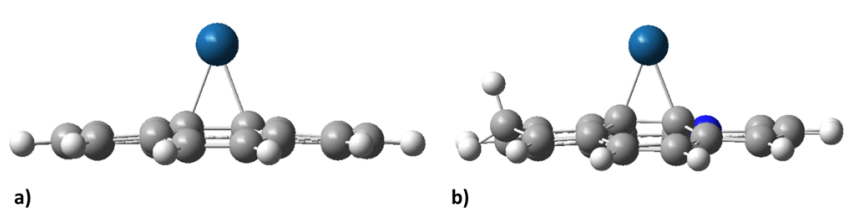

Figure 6. Side profile views of Pt over the control (a) and singlet (b) two-shell truncated models, demonstrating the conformational change of the carbon surface from the metal atom adsorption.

While the nitrogen individually does not drastically change the carbon lattice, the combination of the defect metal with the geometric flexibility from nitrogen is inducing the conformational change. The energetic cost of this initial reshaping, although subtle in the broader scheme of a graphene sheet (explains the difference in magnitudes), is outweighed by the favorable $\mathbf{E}_{\text {ads }}$, as shown in Table 2 . The significantly higher

Table 2. Energetic Penalties of the Conformational Changes by Comparing the Energies of a Support vs a Metal Support (in eV) in the Two-Shell Truncated Undoped and Doped Singlet Models for Each Metal as Calculated Using PBE1PBE/6-31+G(d) \& def2-TZVPD

$\begin{array}{lcc} & \text { undoped } & \text { doped } \\ \mathrm{Fe} & 0.36 & 0.56 \\ \mathrm{Ru} & 0.52 & 1.52 \\ \mathrm{Os} & 0.61 & 1.02 \\ \mathrm{Co} & 0.31 & 1.07 \\ \mathrm{Rh} & 0.69 & 0.81 \\ \mathrm{Ir} & 0.65 & 1.02 \\ \mathrm{Ni} & 0.29 & 0.74 \\ \mathrm{Pd} & 0.37 & 0.65 \\ \mathrm{Pt} & 0.58 & 0.94 \\ \mathrm{Cu} & 0.28 & 0.36 \\ \mathrm{Ag} & 0.28 & 0.29 \\ \mathrm{Au} & 0.28 & 0.52\end{array}$

energetic cost in the doped models aligns with their much more favorable $\mathbf{E}_{\text {ads }}$. For all metals, the energetic penalty of supporting a metal from a pristine (no metal) support is greater in the doped supports than the undoped support; the difference also roughly correlates with the increase in adsorption seen with doping. The conformational change could contribute to reducing strain imposed by metal nucleation, especially with larger metals. This initial cost is ultimately overcome with a much more favorable $\mathbf{E}_{\text {ads }}$. When compared to the three-shell equivalent, this effect is less expressive with a comparatively less favorable $\mathbf{E}_{\text {ads }}$. Never- 
Table 3. Charge (q), the Electron Occupancy in the Valence s-Orbital (s), and the Electron Occupancy in the Valence pOrbital (p) of the Graphitic Defect Nitrogen and the Corresponding Carbon in the Undoped Control along with the Three Adjacent Carbon Atoms between the Two-Shell and Three-Shell Truncated Models from NBO Analysis with PBE1PBE/6$31+G(d) \&$ def2-TZVPD

\begin{tabular}{|c|c|c|c|c|c|c|c|c|}
\hline & \multicolumn{2}{|c|}{$\mathrm{C}$ or $\mathrm{N}$} & \multicolumn{2}{|c|}{ adjacent C \#1 } & \multicolumn{2}{|c|}{ adjacent $\mathrm{C} \# 2$} & \multicolumn{2}{|c|}{ adjacent C \#3 (edge) } \\
\hline & undoped & doped & undoped & doped & undoped & doped & undoped & doped \\
\hline$q$ & -0.01 & -0.27 & -0.01 & 0.22 & -0.01 & 0.20 & -0.06 & 0.17 \\
\hline $\mathrm{s}$ & 0.88 & 1.18 & 0.88 & 0.85 & 0.88 & 0.85 & 0.90 & 0.87 \\
\hline $\mathrm{p}$ & 3.11 & 4.08 & 3.11 & 2.91 & 3.11 & 2.93 & 3.14 & 2.94 \\
\hline
\end{tabular}

Table 4. Charge (q), the Electron Occupancy of the Metal Atom's Valence d-Orbitals (d), and the Electron Occupancy of the Metal Atom's Valence s-Orbital (s) between the Series of 12 Metals over the Undoped and Doped Truncated Two-Shell along with the Change from Undoped to Doped from NBO Analysis with PBE1PBE/6-31+G(d) \& def2-TZVPD

\begin{tabular}{|c|c|c|c|c|c|c|c|c|c|}
\hline & \multicolumn{3}{|c|}{ undoped } & \multicolumn{3}{|c|}{ doped } & \multicolumn{3}{|c|}{ change from undoped to doped } \\
\hline & $\mathrm{q}$ & d & $\mathbf{s}$ & $\mathrm{q}$ & $\mathrm{d}$ & $\mathbf{s}$ & $\Delta \mathrm{q}$ & $\Delta \mathrm{d}$ & $\Delta \mathrm{s}$ \\
\hline $\mathrm{Fe}$ & 0.41 & 7.37 & 0.06 & 0.42 & 7.38 & 0.07 & 0.01 & 0.01 & 0.01 \\
\hline $\mathrm{Ru}$ & 0.30 & 7.53 & 0.07 & 0.20 & 7.58 & 0.17 & -0.10 & 0.05 & 0.10 \\
\hline Os & 0.40 & 7.35 & 0.14 & 0.10 & 6.72 & 1.15 & -0.30 & -0.63 & 1.01 \\
\hline Co & 0.10 & 7.85 & 0.98 & 0.49 & 7.98 & 0.51 & 0.39 & 0.13 & -0.47 \\
\hline $\mathrm{Rh}$ & 0.27 & 8.36 & 0.36 & 0.21 & 8.53 & 0.25 & -0.06 & 0.17 & -0.11 \\
\hline Ir & 0.24 & 8.19 & 0.54 & 0.05 & 8.02 & 0.90 & -0.19 & -0.17 & 0.36 \\
\hline $\mathrm{Ni}$ & 0.40 & 9.41 & 0.06 & 0.28 & 9.33 & 0.36 & -0.12 & -0.08 & 0.30 \\
\hline $\mathrm{Pd}$ & 0.25 & 9.65 & 0.08 & 0.16 & 9.55 & 0.27 & -0.09 & -0.10 & 0.19 \\
\hline Pt & 0.20 & 9.41 & 0.37 & -0.03 & 9.22 & 0.79 & -0.23 & -0.19 & 0.42 \\
\hline $\mathrm{Cu}$ & -0.01 & 9.99 & 1.00 & 0.01 & 9.93 & 1.02 & 0.01 & -0.06 & 0.02 \\
\hline $\mathrm{Ag}$ & 0.00 & 10.00 & 1.00 & -0.02 & 9.99 & 1.01 & -0.01 & -0.01 & 0.01 \\
\hline $\mathrm{Au}$ & 0.01 & 9.89 & 1.07 & -0.18 & 9.85 & 1.30 & -0.19 & -0.04 & 0.23 \\
\hline
\end{tabular}

theless, this subtlety is relevant in models with edges or vacancies where this conformational change would be present. Furthermore, this may play a much larger role in stability as the addition of nitrogen allows for greater spatial flexibility around the defect for the metal to nucleate.

These trends are further highlighted and explained with natural bonding orbital (NBO) analysis on the truncated models. A basis was first established by performing $\mathrm{NBO}$ analysis on the two-shell doped and undoped supports without the metals (see Table 3). The charge and electron density, defined by electronic occupation of the atom's valence orbitals, of the nitrogen (carbon in the case of the undoped) and the bonded adjacent carbon atoms (one being an edge carbon). The nitrogen graphitic defect made the adjacent carbon atoms relatively more electropositive, which is in agreement with previous computational results. ${ }^{7}$ Furthermore, this effect may propagate even further than the neighboring carbons and is the fundamental force driving metal adsorption as suggested by MOA at the edge and further away from the defect.

From the NBO analysis of metal-support structures, it was observed that the electron-deficient carbons exchange electron density with the metal, as presented in Table 4 . This exchange is metal-dependent but once again reinforcing that there is no direct interaction with nitrogen.

From Table 4, the electron density of the metal is shifted from its valence d-orbitals up to its valence s-orbital or taken up by the carbon support except for Co. The electronic reorganization of the metal's orbitals is necessary for this interaction between metal adsorption to the carbon support as there is better orbital overlap between the metal's s-orbital and the carbon's p-orbital than with any of the metal's d-orbitals. This is further supported by examining the highest occupied molecular orbitals (HOMOs) of the metal-graphene com- plexes, as shown in Figure 7. In the undoped supports, the metal's d-orbitals are intact and noninteracting with the graphene surface. However, in the doped supports, the frontier orbitals of metals gain more $s$-character and show increased interaction with the carbons. The agreement between the NBO analysis and molecular orbital analysis supports that this electronic shift is the fundamental interactions that guide the improvements of catalyst-supports with nitrogen doping.

The systematic trends can be described under the lens of these fundamental interactions. Moving across the periodic table starting at group 8 and ending at group 11, the relative magnitude of adsorption decreases. Concurrently, the metals' d-orbital becomes more filled until they become completely filled in group 11. The highly occupied d-orbitals provide stability, thus making the metal less likely to promote those electrons up to the valence s-orbital, limiting the possible orbital overlap with the support carbons. Therefore, group 8 has the most favorable $\mathbf{E}_{\text {ads }}$ (based on absolute values) as its $\mathrm{d}$ orbitals are the emptiest compared to the other groups and are more easily promoted to interact with the graphene surface. This is also reinforced with its main MOA of $\mathrm{H}$ as this site allows for the noninteracting emptier d-orbitals to be far from any of the surface atoms. As metals' d-orbitals become more filled, the MOA shifts to CC in groups 9 and 10 and to $C$ in group 11. With greater occupancy of the d-orbitals, the metals' valence $s$-orbital then interacts closer to the carbons, although to a lesser degree. There is a less promotion of electron density from the support when the metals themselves already maintain more filled stable d-orbitals. This correlates with the trend in which the increase in adsorption favorability from doping decreases moving from group 8 to group 11 .

It is possible that since group 11 metals have full d-orbitals, they may simply not interact at all with carbon atoms, given 


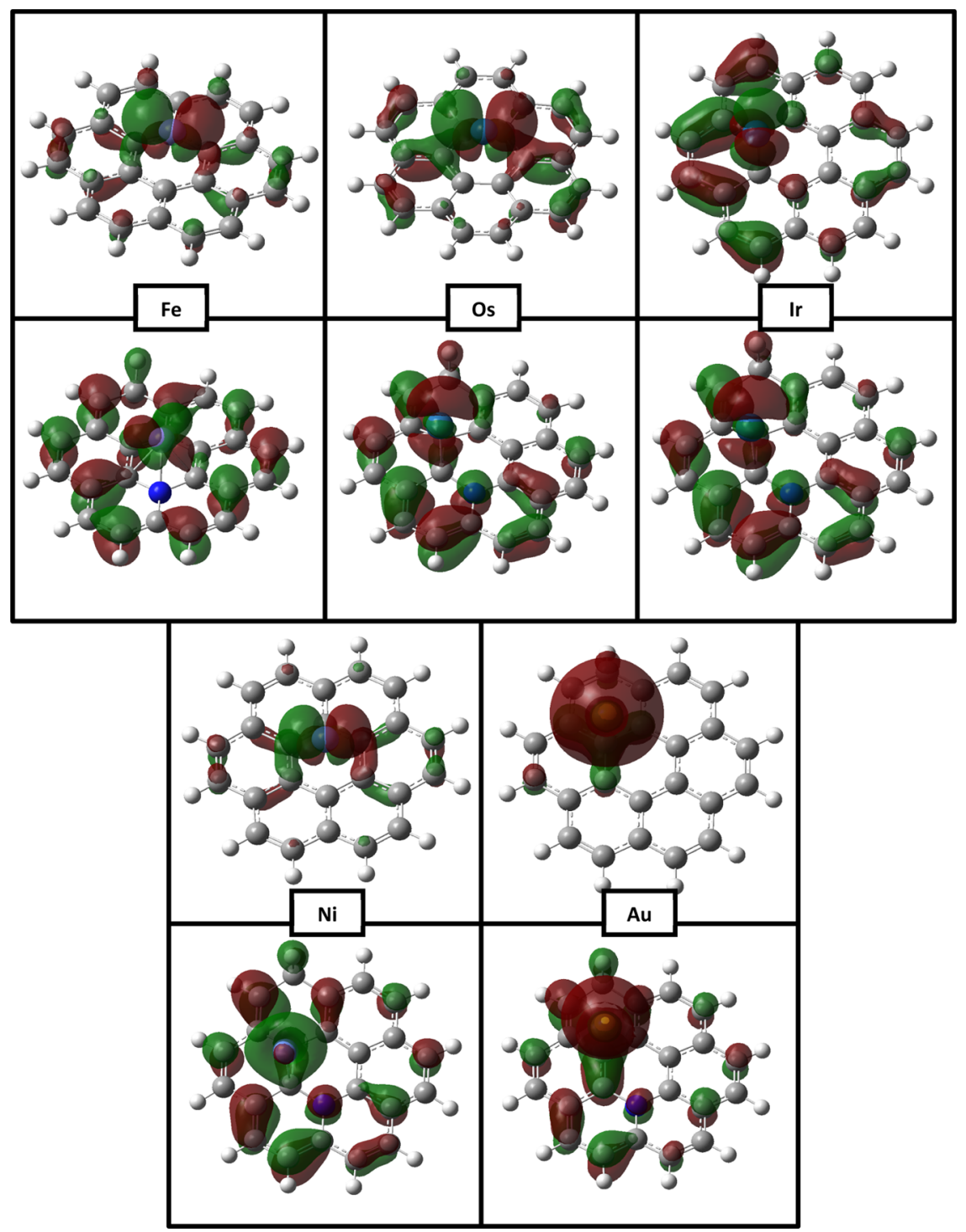

Figure 7. HOMO isosurfaces (isovalue $=0.03$ ) of select representative metals from each group (two from group 8 to display the effect of metal size, $\mathrm{Ni}$ and $\mathrm{Ir}$ as they best display this electronic shift for their groups, and Au showing how its group's natural valence full d-shell and half-filled sshell hinders the observed electronic shift) with the undoped (top) and doped (bottom) two-shell surfaces.

their lack of orbital overlap and almost zero electronic rearrangement and adsorption energies (except for Au where it has nonzero values but still low when compared to other groups). The C MOA may be the location where there is the least number of possible interactions, and thus, the metal settles there considering destabilization in the other MOAs. Spatially, group 11 is much further away (in the $z$-axis) from the surface. All other metals are within $2 \AA$ of the surface, while group 11 metals are as far as $3 \AA$, both in doped and undoped cases, indicating a lack of overall electronic interaction between the metal and the surface. Similarly, Pd shares the same full dorbital configuration as group 11, explaining its lack of increase in adsorption favorability with doping and overall lower adsorption energies when compared to its own group counterparts of $\mathrm{Ni}$ and $\mathrm{Pt}$.

In terms of periods, period 6 metals (Os, Ir, $\mathrm{Pt}$, and $\mathrm{Au}$ ) have the highest adsorption energies relative to their respective group, corresponding to the electronic shift seen in Table 4. First, their larger size plays a role in allowing their orbitals to better overlap with carbon atom orbitals. Second, even though they are having a similar size to period 5 metals $(\mathrm{Ru}, \mathrm{Rh}, \mathrm{Pd}$, and $\mathrm{Ag}$ ) due to contraction, they contain relativistic effects. These effects destabilize the 5d-orbitals, increasing their distance from the nucleus and decreasing the 6s-orbital distance in conjuncture, making the valence $5 \mathrm{~d}$ to $6 \mathrm{~s}$ transition energy gap smaller. ${ }^{82}$ That second factor may not be as significant as $\mathrm{Ru}$ and $\mathrm{Os}$ have very similar adsorption energies.

The nitrogen graphitic defect provides increased favorability for adsorption with an increase in $\mathbf{E}_{\text {ads }}$ from about 0.5 to $1.0 \mathrm{eV}$ for all groups except group 11. Group 11 was determined to not have any notable adsorption (although seemingly Au does have the greatest percentage-based increase with doping). Thus, with this model, it appears that the most significant effect from graphitic nitrogen defects on adsorption and MSI is with group 8, Rh and Ir from group 9, and $\mathrm{Ni}$ and $\mathrm{Pt}$ from group 10 .

2.2. Periodic Models. So far, the metal-support interactions have been discussed in terms of the truncated models. As previously mentioned, an alternate way to computationally treat the graphene surface with DFT is 
using a planewave basis set with atomic pseudopotentials and periodic boundary conditions (PBC). This methodology allows a closer representation to the periodic nature of the graphene surface. To further probe the metal-support interactions, a PBC model was prepared as an $8 \times 8$ unit cell (vide supra, Figure 3), representative of the two-shell truncated model in terms of nitrogen atomic density. Twodimensional-smaller $4 \times 4$ unit cells were also created in isolating the effect the unit cell size has on the metal-support interactions. First, $4 \times 4$ unit cell A represents the entire $8 \times 8$ unit cell just with smaller dimensions, meaning the same number of graphitic defects as the $8 \times 8$ unit cell, and second, $4 \times 4$ unit cell B represents only a section of the $8 \times 8$ unit cell, that is the same density of graphitic defects (see Figure S2). Figure 8 displays the resulting $\mathbf{E}_{\text {ads }}$ and MOA of the 12 metals with those three-unit cells along with comparison to an equivalent undoped support.

In terms of the undoped support representing pristine graphene, there was little to no effect on the adsorption energies between both $4 \times 4$ and the $8 \times 8$ unit cells. The only
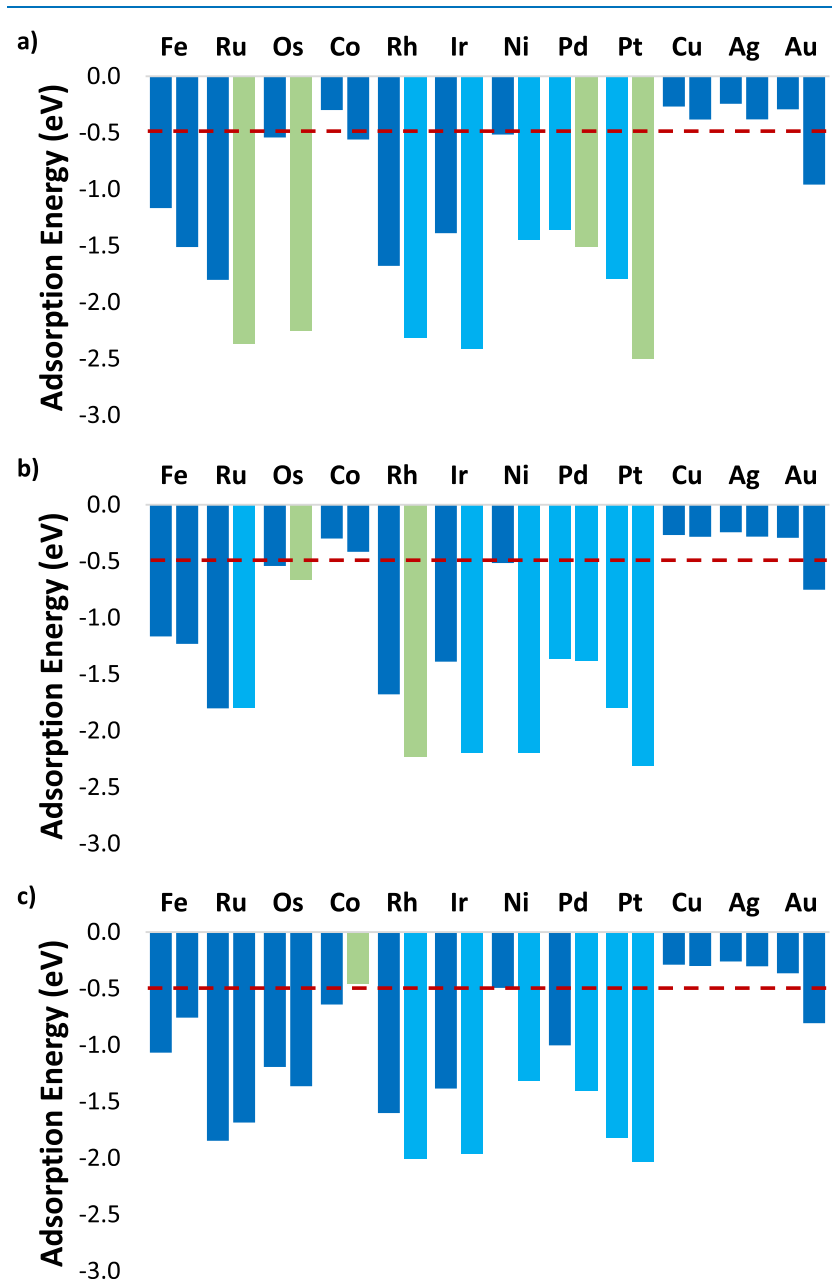

Figure 8. Adsorption energies and MOA of the metals with the surfaces of the different unit cells: (a) $4 \times 4$ unit cell A, (b) $4 \times 4$ unit cell $\mathbf{B}$, and (c) $8 \times 8$ unit cell. Each metal has two bars where the left one refers to the undoped support and the right one refers to the doped equivalent. The different colors of the bar represent the MOA: dark blue is over $\mathrm{H}$, light blue is over $\mathrm{CC}$, and green is over $\mathrm{C}$. The red line indicates the $-0.5 \mathrm{eV}$ threshold for particle migration at room temperature. metals with greater than about a $0.1 \mathrm{eV}$ difference in $\mathbf{E}_{\text {ads }}$ were Os with a $0.54 \mathrm{eV}$ difference, Co with a $0.34 \mathrm{eV}$ difference, and $\mathrm{Pd}$ with a $0.36 \mathrm{eV}$ difference (Pd has a different MOA). All metals also had H MOA, except for Pt and Pd (which had CC MOA).

Comparing all the doped supports across all the unit cells, Co and group 11 have relatively insignificant adsorption to the sheet (with Co having a different MOA in the $8 \times 8$ ). Fe, $\mathrm{Ru}$, $\mathrm{Rh}, \mathrm{Ir}, \mathrm{Pd}$, and Pt have about the same $\mathrm{E}_{\mathrm{ads}}$ throughout the unit cells, with minor differences in MOA. For the metals that retain the MOA between the different unit cells, the magnitude of $\mathbf{E}_{\text {ads }}$ is usually predicted to be slightly greater in $4 \times 4$ unit cells as compared to that in the $8 \times 8$. Ni and Os adsorption energies differ by more than $1 \mathrm{eV}$ between the doped versions of all the unit cells; $\mathrm{Ni}$ has the same MOA in all unit cells, while Os has different MOAs between the $4 \times 4$ unit cells and the $8 \times 8$ unit cells. Comparing the $4 \times 4$ unit cells to each other, results from unit cell $\mathbf{A}$ showed higher magnitudes of $\mathbf{E}_{\text {ads }}$ by about of $0.1-0.5 \mathrm{eV}$ for most metals and different MOAs for $\mathrm{Ru}, \mathrm{Rh}, \mathrm{Pd}$, and Pt than those for the unit cell $\mathbf{B}$. The chemical structure of the surface differs significantly between the two $4 \times 4$ unit cells because cell $\mathbf{A}$ may not be representative of stable physical materials, given the proximity of the graphitic defects. This would also explain the difference of MOA as compared to the other two unit cells. Overall, there is more similarity between unit cell $\mathbf{B}$ and the $8 \times 8$ unit cell than the unit cell $\mathbf{A}$, denoting that unit cells based on a similar morphology are viable in reproducing similar metal-support interactions. There are still subtle differences among these two similar unit cells as the $8 \times 8$ unit cell shows loss of adsorption favorability with doping for $\mathrm{Fe}$ and $\mathrm{Ru}$ along with the small differences in adsorption energies and MOA. Nevertheless, unit cells with a similar chemical structure show mostly consistent results. Results only from the $8 \times 8$ unit cell will be discussed in the next section for clarity.

2.3. Model Comparison. Although previous discussions have focused only on either truncated or periodic models of the carbon support, it is important to compare results from both models. The MOAs for all metals are generally similar in the two-shell truncated model, in the three-shell truncated model, and in the periodic model with the $8 \times 8$ unit cell. The same trends concerning relative magnitudes of adsorption are also similar between models. For metals from groups 8 , 9, and 10 , the magnitude of adsorption energies in the truncated models is greater than that of the PBC model by around 1.0 $\mathrm{eV}$. The differences in $\mathbf{E}_{\text {ads }}$ between doped and undoped surfaces also decrease moving from the two-shell model to the three-shell model to the PBC model. This difference in energy could be explained with the much higher flexibility for conformational change within the three-shell and $\mathrm{PBC}$ model. Metals with CC MOA changed their adsorption from one $\mathrm{C}-\mathrm{C}$ bond to another $\mathrm{C}-\mathrm{C}$ bond when comparing twoshell models to the three-shell and PBC models. Also, the new CC MOA in the three-shell model was the carbon-carbon bond furthest away from the nitrogen within the inner hole containing nitrogen. This shift in MOA between the models could be a product of the conformation flexibility as discussed above. The major difference between the truncated and PBC models would be in the MOA on their undoped surfaces. As previously stated, mostly all metals in the PBC model had $\mathrm{H}$ MOA with the undoped surface. This suggests that there are no favorable interactions that surpass the $\mathrm{H}$-starting location 
because the $\mathrm{H}$ site offers the most amount of orbital overlap with graphene.

Results for metals from group 8 have the most discrepancies when comparing different models, especially the PBC model as it does not show improvement upon doping, while the truncated models do. Os is also problematic as its treatment shows large differences in $\mathbf{E}_{\text {ads }}$ between the two-shell truncated and PBC models along with different MOA. Moreover, Os did not optimize with the three-shell model presumably due to the large, induced conformational change in graphene and was only feasible in the two-shell model. In group 9, Rh and Ir from the PBC model match the truncated models, in terms of improvement of adsorption favorability with the dopant. Co is an outlier in this group. Co, like Os, had variable results such as no optimization with the doped three-shell model, a loss of favorable adsorption with doping in the PBC model, and no favorable two-shell adsorption as the bar shown in Figure 5 corresponds to an edge MOA. In group 10, there is one difference between models aside from the general observations. This difference revolves around Pd's interaction with the support. $\mathbf{E}_{\text {ads }}$ favorability tends to increase when moving down in a group. With $\mathrm{Pd}$, however, it has a lower adsorption to the undoped and doped support when compared to $\mathrm{Ni}$ and $\mathrm{Pt}$. This is attributed to the filled d-orbitals and unique valence configuration of Pd. Its electronic nature is closer to that of group 11 and thus behaves similarly. For group 11, the same trend is confirmed as there is little favorable adsorption for these metals with the graphene surface across all models. However, there is a consistent notable increase for the adsorption of $\mathrm{Au}$ due to nitrogen doping when compared to $\mathrm{Cu}$ and $\mathrm{Ag}$, presenting some promise for further investigation.

Based on the discussion above, it is concluded that $\mathrm{Rh}, \mathrm{Ir}$, $\mathrm{Ni}, \mathrm{Pd}, \mathrm{Pt}$, and $\mathrm{Au}$ would be the preferred candidates when compared to the rest of the 12 metals considered in having an improved MSI upon nitrogen doping with graphitic nitrogen defects. Agreement between all models also indicates that Co, $\mathrm{Cu}$, and $\mathrm{Ag}$ would have significant effect on their interaction with the carbon support upon the introduction of graphitic nitrogen defect. The truncated models support that $\mathrm{Fe}$ and $\mathrm{Ru}$ would also be catalysts that gain favorable adsorption with doping. On the other hand, the PBC model showed that $\mathrm{Fe}$ and $\mathrm{Ru}$ do not have more favorable adsorption with doping but Os does. Further investigations into $\mathrm{Os}, \mathrm{Co}, \mathrm{Ni}$, and $\mathrm{Au}$ would assist in addressing the variations shown and better interpret the systematic trends ( $\mathrm{Os}$ and $\mathrm{Co}$ had inconsistencies throughout all their calculations, while $\mathrm{Ni}$ and $\mathrm{Au}$ have the small subtleties). In terms of the model system for the study of the interactions, PBC may be the best choice, considering the more conservative increase with adsorption favorability in doping and the portrayal of a graphene sheet regarding the truncated conformational change, if the unit cell is strategically designed. Despite that the truncated models still proved viable in producing the same systematic trends that were key in elucidating the fundamental interactions.

\section{CONCLUSIONS}

While the practicality for some of these metals to be used in catalysis may be relatively low, the comparison across multiple groups and periods provides informative insights into how the metals interact with the carbon support. These findings suggest which metals might benefit from being supported on the $\mathrm{N}$ doped support as opposed to undoped carbon. This study improved a foundation for computationally examining the stabilization of metal catalysts over carbon supports with graphitic nitrogen through a systematic investigation in examining the treatment of truncated models, role of the unit cell within PBC models, and comparability between those two types of models. This study utilized three different computational approaches, doublet and singlet treatment of truncated support models, and periodic support models to investigate the impact of graphitic nitrogen defect in the carbon support on 12 different transition metals. It was found that the type of interaction between the metal and support for the series of metals was preserved, but the strength of that interaction had a dependence on the elements of the computational treatment. The MOA was guided by the metals' d-orbital electronic density rearranging to interact with the surface. Given the less-weighted importance of the magnitude of adsorption, the study presents the viability of a truncated model in achieving the same conclusions compared to the PBC model for a systematic study. Overall, a basis for more detailed computational catalyst adsorption and nucleation studies was established, in which other catalytic properties could then be explored. Thus, the study establishes a parameter space for both models to decide which model is more suitable for certain investigations on other defects and metal combinations moving forward.

\section{COMPUTATIONAL METHODS}

The $\mathrm{N}$-doped graphene was prepared with a single graphitic defect and represented in two ways. The first representation uses truncated models, where graphene is truncated to two or three "shells" (see Figure 1) where edges are passivated with hydrogen atoms, and the second representation contains extended surfaces using PBCs, where a unit cell is surrounded with periodic images to represent the periodic nature of graphene. This study evaluates the electronic interactions between the $\mathrm{N}$-doped graphene and metals from four periodic groups, group 8: $\mathrm{Fe}, \mathrm{Ru}$, and $\mathrm{Os}$; group 9: $\mathrm{Co}, \mathrm{Rh}$, and $\mathrm{Ir}$; group 10: $\mathrm{Ni}, \mathrm{Pd}$, and $\mathrm{Pt}$; and group 11: $\mathrm{Cu}, \mathrm{Ag}$, and $\mathrm{Au}$.

4.1. Truncated Models. The truncated models were studied using DFT calculations as implemented in the Gaussian09 software package. ${ }^{66}$ Two truncated models with a single nitrogen graphitic defect at their centers were created, referred to as two- and three-shell (Figure 1), along with the corresponding undoped control models. The two-shell model was treated both as a doublet and as a singlet electronic configuration with the graphitic nitrogen defect, referred to as doublet and singlet, respectively (see Figure S1). In the doublet scenario, a lone unpaired electron from the nitrogen defect was considered in the calculations, while in the singlet case, the lone electron was artificially treated by hybridizing an edge carbon atom as an $\mathrm{sp}^{3}$ carbon. ${ }^{7,67}$ The three-shell was prepared only in the singlet form to evaluate the presence of edge effects on the metal-graphene electronic interactions presented in the two-shell.

The 12 metals were optimized above the two-shell (in the $z$ axis with the graphene sheet spanning along the $x$ - and $y$-axes) starting at the four different locations shown in Figure 2 using four different DFT functionals. The hybrid Becke 3-parameter exchange functional with the Lee-Yang-Parr correlation functional (B3LYP) was used because of its widespread conventional and reliable usage between metals and organic molecules including some other related truncated model studies. $^{22,34,48,63,67-69}$ The hybrid range-separated Becke 97 functional modified by Head-Gordon and coworkers 
$(\omega \mathrm{B} 97 \mathrm{xd})$ through long-range corrections with empirical dispersion was used in examining the noncovalent dispersion interactions between the metal-support and to compare to the short-range interactions of B3LYP. ${ }^{55}$ The nonempirical PBE1PBE functional was chosen for its commonplace use among solid-state physics and $\mathrm{N}$-doped carbon materials. ${ }^{70-72}$ Last, the more expensive hybrid HSE functional was used as a benchmark comparison through Gaussian16 as it extends the PBE functional by partitioning into short- and long-range interactions with Coulombic screening and empirical formulation, improving the treatment of materials, such as by increasing the accuracy of band gap calculations. ${ }^{7,73-75}$ For all the aforesaid calculations, $6-31+G(d)$ basis sets were used for all atoms except the metals for which the def2-TZVPD basis set was utilized. The electronic distributions/interactions were examined by performing NBO calculations as described in the Results and Discussion section. ${ }^{76}$

Counterpoise corrections were used to account for basis set superposition error when calculating the adsorption energy where the negative values were defined as favorable interactions. The adsorption energy was calculated through

$$
\mathbf{E}_{\mathrm{ads}}=\mathbf{E}_{\mathbf{M S}}-\mathbf{E}_{\mathbf{M}}-\mathbf{E}_{\mathbf{S}}
$$

where $\mathbf{E}_{\text {ads }}$ is the counterpoise corrected adsorption energy, $\mathbf{E}_{\mathbf{M S}}$ is the energy of the metal-support complex, and $\mathbf{E}_{\mathbf{M}}$ and $\mathbf{E}_{\mathbf{S}}$ are the energies of the metal and support, respectively, corrected through counterpoise.

4.2. PBC Models. PBC models were studied using planewave-DFT implemented in the Quantum Espresso 6.4 package. ${ }^{77}$ The PBE generalized gradient approximation exchange-correlation functional coupled with projectoraugmented-wave pseudopotentials for spin-polarized calculations of the periodic boundary models were employed to accurately study the metal-graphene interactions. ${ }^{77-80} \mathrm{~A}$ kinetic cutoff energy of $40 \mathrm{Ry}$ and $2 \times 2 \times 1 \Gamma$-point Monkhorst-Pack-based $k$-point grid were utilized for the relaxation of the metal atoms starting from the $\mathrm{H}$ position. Adsorption energies of the PBC models were calculated with

$$
\mathbf{E}_{\mathrm{ads}}=\mathbf{E}_{\mathrm{UC}, \mathrm{MS}}-\mathbf{E}_{\mathrm{UC}, M}-\mathbf{E}_{\mathrm{UC}, \mathrm{S}}
$$

where $\mathbf{E}_{\mathrm{ads}}$ is the adsorption energy of the metal to the support, $\mathbf{E}_{\mathrm{UC}, \mathrm{MS}}$ is the total energy of the unit cell with the support and metal, $\mathbf{E}_{\mathrm{UC}, \mathrm{M}}$ is the energy of the unit cell with just the metal, and $\mathbf{E}_{\mathrm{UC}, \mathrm{S}}$ is the energy of the unit cell with just the support.

Two differently sized unit cells of graphene were used with a $15 \AA$ vacuum region between periodic layers of graphene: a $4 \times$ 4 unit cell and an $8 \times 8$ unit cell ( 32 and 128 atoms total, respectively, Figure 3 ). The $8 \times 8$ unit cell was designed in having four evenly spaced graphitic defects to approximately match the truncated two-shell model dopant density by atom. Kinetic cutoff energy and $k$-point grid convergence were examined with the $8 \times 8$ unit cell by independently increasing the kinetic energy cutoff from $40 \mathrm{Ry}$ to $50 \mathrm{Ry}$ and the Monkhorst-Pack-based $k$-point grid from $2 \times 2 \times 1$ to $4 \times 4 \times$ 1. For the kinetic cutoff energy convergence, all metals had less than $0.03 \mathrm{eV}$ change in $\mathbf{E}_{\text {ads }}$ except for $\mathrm{Rh}, \mathrm{Fe}$, and $\mathrm{Co}$, which all had changes between 0.1 and $0.2 \mathrm{eV}$. For the $k$-point grid convergence, the highest change observed between all metals was $0.08 \mathrm{eV}$. This energetic discrepancy still leaves the $\mathbf{E}_{\text {ads }}$ magnitudes, except for Co, outside of ambiguity when considering the threshold for atomic room-temperature migration. ${ }^{64}$ Considering the systematic and comparative scope of the study, the additional computational expense for higher kinetic cutoff energy and k-point grid is not necessary. For the $4 \times 4$ cell, two forms were designed by varying the number of graphitic defects (see Figure S2). The first (referred to as $4 \times 4$ cell $\mathbf{A}$ ) contains four graphitic defects, the same number of defects as the $8 \times 8$ cell, and the second (referred to as $4 \times 4$ cell $B$ ) contains graphitic defects equivalent to the nitrogen density by atom as the $8 \times 8$ cell (only one nitrogen defect).

\section{ASSOCIATED CONTENT}

\section{(5) Supporting Information}

The Supporting Information is available free of charge at https://pubs.acs.org/doi/10.1021/acsomega.1c04306.

Visual representation of the doublet versus the singlet form, visual representation of cells $\mathbf{A}$ and $\mathbf{B}$, all the Ads. E. and MOA across all parameters, all information obtained from NBO analysis, and all isosurfaces of the HOMO level obtained (PDF)

\section{AUTHOR INFORMATION}

\section{Corresponding Author}

Shubham Vyas - Department of Chemistry, Colorado School of Mines, Golden, Colorado 80401, United States;

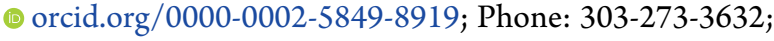
Email: svyas@mines.edu; Fax: 303-273-3629

\section{Authors}

Vu Nguyen - Department of Chemistry, Colorado School of Mines, Golden, Colorado 80401, United States

Brian D. Etz - Department of Chemistry, Colorado School of Mines, Golden, Colorado 80401, United States; (1) orcid.org/0000-0002-0855-4863

Svitlana Pylypenko - Department of Chemistry, Colorado School of Mines, Golden, Colorado 80401, United States; (1) orcid.org/0000-0001-7982-734X

Complete contact information is available at: https://pubs.acs.org/10.1021/acsomega.1c04306

\section{Notes}

The authors declare no competing financial interest.

\section{ACKNOWLEDGMENTS}

This work was funded by the National Science Foundation (CHE-1800585). The authors also acknowledge the computational resources allocated by the high-performance computing facility at the Colorado School of Mines.

\section{REFERENCES}

(1) Chen, D.; Tang, L.; Li, J. Graphene-Based Materials in Electrochemistry. Chem. Soc. Rev. 2010, 39, 3157-3180.

(2) Antolini, E. Graphene as a New Carbon Support for LowTemperature Fuel Cell Catalysts. Appl. Catal., B 2012, 123-124, 5268.

(3) Dai, L.; Xue, Y.; Qu, L.; Choi, H.-J.; Baek, J.-B. Metal-Free Catalysts for Oxygen Reduction Reaction. Chem. Rev. 2015, 115, 4823-4892.

(4) Wood, K. N.; O’Hayre, R.; Pylypenko, S. Recent Progress on Nitrogen/Carbon Structures Designed for Use in Energy and Sustainability Applications. In Energy and Environmental Science; Royal Society of Chemistry, 2014; Vol. 7, pp 1212-1249. DOI: $10.1039 / \mathrm{c} 3$ ee44078h.

(5) Paraknowitsch, J. P.; Thomas, A. Doping Carbons beyond Nitrogen: An Overview of Advanced Heteroatom Doped Carbons 
with Boron, Sulphur and Phosphorus for Energy Applications. Energy Environ. Sci. 2013, 6, 2839-2855.

(6) Vinayan, B. P. Heteroatom-Doped Graphene-Based Hybrid Materials for Hydrogen Energy Conversion. In Recent Advances in Graphene Research; InTech, 2016, pp 177-194. DOI: 10.5772/64242.

(7) Muhich, C. L.; Westcott, J. Y.; Morris, T. C.; Weimer, A. W.; Musgrave, C. B. The Effect of N and B Doping on Graphene and the Adsorption and Migration Behavior of Pt Atoms. J. Phys. Chem. C 2013, 117, 10523-10535.

(8) Antolini, E.; Salgado, J. R. C.; Gonzalez, E. R. The Stability of Pt$M(M=$ First Row Transition Metal) Alloy Catalysts and Its Effect on the Activity in Low Temperature Fuel Cells. A Literature Review and Tests on a Pt-Co Catalyst. J. Power Sources 2006, 160, 957-968.

(9) Shao, Y.; Yin, G.; Gao, Y. Understanding and Approaches for the Durability Issues of Pt-Based Catalysts for PEM Fuel Cell. J. Power Sources 2007, 171, 558-566.

(10) Mayur, M.; Gerard, M.; Schott, P.; Bessler, W. Lifetime Prediction of a Polymer Electrolyte Membrane Fuel Cell under Automotive Load Cycling Using a Physically-Based Catalyst Degradation Model. Energies 2018, 11, 2054.

(11) Holby, E. F.; Sheng, W.; Shao-Horn, Y.; Morgan, D. Pt Nanoparticle Stability in PEM Fuel Cells: Influence of Particle Size Distribution and Crossover Hydrogen. Energy Environ. Sci. 2009, 2, 865-871.

(12) Artyushkova, K.; Serov, A.; Rojas-Carbonell, S.; Atanassov, P. Chemistry of Multitudinous Active Sites for Oxygen Reduction Reaction in Transition Metal-Nitrogen-Carbon Electrocatalysts. J. Phys. Chem. C 2015, 119, 25917-25928.

(13) Zhou, Z.-M.; Shao, Z.-G.; Qin, X.-P.; Chen, X.-G.; Wei, Z.-D.; Yi, B.-L. Durability Study of Pt-Pd/C as PEMFC Cathode Catalyst. Int. J. Hydrogen Energy 2010, 35, 1719-1726.

(14) Liu, K.; Qiao, Z.; Hwang, S.; Liu, Z.; Zhang, H.; Su, D.; Xu, H.; Wu, G.; Wang, G. Mn- and N- Doped Carbon as Promising Catalysts for Oxygen Reduction Reaction: Theoretical Prediction and Experimental Validation. Appl. Catal. B Environ. 2019, 243, 195-203.

(15) Chung, H. T.; Cullen, D. A.; Higgins, D.; Sneed, B. T.; Holby, E. F.; More, K. L.; Zelenay, P. Direct Atomic-Level Insight into the Active Sites of a High-Performance PGM-Free ORR Catalyst. Science 2017, 357, 479-484.

(16) Speder, J.; Zana, A.; Spanos, I.; Kirkensgaard, J. J. K.; Mortensen, K.; Hanzlik, M.; Arenz, M. Comparative Degradation Study of Carbon Supported Proton Exchange Membrane Fuel Cell Electrocatalysts - The Influence of the Platinum to Carbon Ratio on the Degradation Rate. J. Power Sources 2014, 261, 14-22.

(17) Perazzolo, V.; Brandiele, R.; Durante, C.; Zerbetto, M.; Causin, V.; Rizzi, G. A.; Cerri, I.; Granozzi, G.; Gennaro, A. Density Functional Theory (DFT) and Experimental Evidences of MetalSupport Interaction in Platinum Nanoparticles Supported on Nitrogen- and Sulfur-Doped Mesoporous Carbons: Synthesis, Activity, and Stability. ACS Catal. 2018, 8, 1122-1137.

(18) Dubau, L.; Castanheira, L.; Chatenet, M.; Maillard, F.; Dillet, J.; Maranzana, G.; Abbou, S.; Lottin, O.; De Moor, G.; El Kaddouri, A.; et al. Carbon Corrosion Induced by Membrane Failure: The Weak Link of PEMFC Long-Term Performance. Int. J. Hydrogen Energy 2014, 39, 21902-21914.

(19) Martinez, U.; Komini Babu, S.; Holby, E. F.; Zelenay, P. Durability Challenges and Perspective in the Development of PGMFree Electrocatalysts for the Oxygen Reduction Reaction. Curr. Opin. Electrochem. 2018, 9, 224-232 Elsevier B.V..

(20) Osmieri, L.; Park, J.; Cullen, D. A.; Zelenay, P.; Myers, D. J.; Neyerlin, K. C. Status and Challenges for the Application of Platinum Group Metal-Free Catalysts in Proton-Exchange Membrane Fuel Cells. Curr. Opin. Electrochem. 2021, 25, 100627 Elsevier B.V..

(21) Yang, Z.; Nie, H.; Chen, X. a.; Chen, X.; Huang, S. Recent Progress in Doped Carbon Nanomaterials as Effective Cathode Catalysts for Fuel Cell Oxygen Reduction Reaction. In Journal of Power Sources; Elsevier B.V., 2013, pp 238-249.

(22) Wang, Y.; Song, W.; Li, M.; Wu, Z. Oxygen Reduction Reaction Mechanisms on Heteroatom-Doped Single-Walled Carbon Nanotube
Catalysts: Insights from a Theoretical Study. J. Electrochem. Soc. 2019, 166, F670-F678.

(23) Wood, K. N.; O’Hayre, R.; Pylypenko, S. Recent Progress on Nitrogen/Carbon Structures Designed for Use in Energy and Sustainability Applications. Energy Environ. Sci. 2014, 7, 1212-1249. (24) Corpuz, A. R.; Olson, T. S.; Joghee, P.; Pylypenko, S.; Dameron, A. A.; Dinh, H. N.; O’Neill, K. J.; Hurst, K. E.; Bender, G.; Gennett, T.; et al. Effect of a Nitrogen-Doped PtRu/Carbon Anode Catalyst on the Durability of a Direct Methanol Fuel Cell. J. Power Sources 2012, 217, 142-151.

(25) Pylypenko, S.; Borisevich, A.; More, K. L.; Corpuz, A. R.; Holme, T.; Dameron, A. A.; Olson, T. S.; Dinh, H. N.; Gennett, T.; O'Hayre, R. Nitrogen: Unraveling the Secret to Stable CarbonSupported Pt-Alloy Electrocatalysts. Energy Environ. Sci. 2013, 6, 2957-2964

(26) Zhao, W.; Zhang, L.; Luo, Q.; Hu, Z.; Zhang, W.; Smith, S.; Yang, J. Single Mo1(Cr1) Atom on Nitrogen-Doped Graphene Enables Highly Selective Electroreduction of Nitrogen into Ammonia. ACS Catal. 2019, 9, 3419-3425.

(27) Hossain, M. D.; Liu, Z.; Zhuang, M.; Yan, X.; Xu, G.-L.; Gadre, C. A.; Tyagi, A.; Abidi, I. H.; Sun, C.-J.; Wong, H.; et al. Rational Design of Graphene-Supported Single Atom Catalysts for Hydrogen Evolution Reaction. Adv. Energy Mater. 2019, 9, 1803689.

(28) Campisi, S.; Chan-Thaw, C.; Villa, A. Understanding Heteroatom-Mediated Metal-Support Interactions in Functionalized Carbons: A Perspective Review. Appl. Sci. 2018, 8, 1159.

(29) Singh, S. K.; Takeyasu, K.; Nakamura, J. Active Sites and Mechanism of Oxygen Reduction Reaction Electrocatalysis on Nitrogen-Doped Carbon Materials. Adv. Mater. 2019, 31, 1804297.

(30) Xing, Z.; Ju, Z.; Zhao, Y.; Wan, J.; Zhu, Y.; Qiang, Y.; Qian, Y. One-Pot Hydrothermal Synthesis of Nitrogen-Doped Graphene as High-Performance Anode Materials for Lithium Ion Batteries. Sci. Rep. 2016, 6, 26146.

(31) Wang, X.; Sun, G.; Routh, P.; Kim, D.-H.; Huang, W.; Chen, P. Heteroatom-Doped Graphene Materials: Syntheses, Properties and Applications. In Chemical Society Reviews; Royal Society of Chemistry October, 2014; Vol. 43, pp 7067-7098. DOI: 10.1039/c4cs00141a.

(32) Zhao, L.; He, R.; Rim, K. T.; Schiros, T.; Kim, K. S.; Zhou, H.; Gutiérrez, C.; Chockalingam, S. P.; Arguello, C. J.; Pálová, L.; et al. Visualizing Individual Nitrogen Dopants in Monolayer Graphene. Science 80 2011, 333, 999-1003.

(33) Axet, M. R.; Durand, J.; Gouygou, M.; Serp, P. Surface Coordination Chemistry on Graphene and Two-Dimensional Carbon Materials for Well-Defined Single Atom Supported Catalysts. In Advances in Organometallic Chemistry; Academic Press Inc., 2019; Vol. 71, pp 53-174.

(34) Kim, J.; Lee, N.; Min, Y. H.; Noh, S.; Kim, N.-K.; Jung, S.; Joo, M.; Yamada, Y. Distinguishing Zigzag and Armchair Edges on Graphene Nanoribbons by X-Ray Photoelectron and Raman Spectroscopies. ACS Omega 2018, 3, 17789-17796.

(35) Workman, M. J.; Dzara, M.; Ngo, C.; Pylypenko, S.; Serov, A.; McKinney, S.; Gordon, J.; Atanassov, P.; Artyushkova, K. Platinum Group Metal-Free Electrocatalysts: Effects of Synthesis on Structure and Performance in Proton-Exchange Membrane Fuel Cell Cathodes. J. Power Sources 2017, 348, 30-39.

(36) Holby, E. F.; Zelenay, P. Linking Structure to Function: The Search for Active Sites in Non-Platinum Group Metal Oxygen Reduction Reaction Catalysts. Nano Energy 2016, 29, 54-64.

(37) Ye, R.; Dong, J.; Wang, L.; Mendoza-Cruz, R.; Li, Y.; An, P.-F.; Yacamán, M. J.; Yakobson, B. I.; Chen, D.; Tour, J. M. Manganese Deception on Graphene and Implications in Catalysis. Carbon 2018, 132, 623-631.

(38) Saha, D.; Kienbaum, M. J. Role of Oxygen, Nitrogen and Sulfur Functionalities on the Surface of Nanoporous Carbons in $\mathrm{CO} 2$ Adsorption: A Critical Review. In Microporous and Mesoporous Materials; Elsevier B.V. October 1, 2019, pp 29-55.

(39) Artyushkova, K.; Kiefer, B.; Halevi, B.; Knop-Gericke, A.; Schlogl, R.; Atanassov, P. Density Functional Theory Calculations of 
XPS Binding Energy Shift for Nitrogen-Containing Graphene-like Structures. Chem. Commun. 2013, 49, 2539-2541.

(40) Artyushkova, K.; Matanovic, I.; Halevi, B.; Atanassov, P. Oxygen Binding to Active Sites of Fe-N-C ORR Electrocatalysts Observed by Ambient-Pressure XPS. J. Phys. Chem. C 2017, 121, 2836-2843.

(41) Schiros, T.; Nordlund, D.; Pálová, L.; Prezzi, D.; Zhao, L.; Kim, K. S.; Wurstbauer, U.; Gutiérrez, C.; Delongchamp, D.; Jaye, C.; et al. Connecting Dopant Bond Type with Electronic Structure in NDoped Graphene. Nano Lett. 2012, 12, 4025-4031.

(42) Holme, T.; Zhou, Y.; Pasquarelli, R.; O’Hayre, R. First Principles Study of Doped Carbon Supports for Enhanced Platinum Catalysts. Phys. Chem. Chem. Phys. 2010, 12, 9461-9468.

(43) Gao, Z.; Li, A.; Li, X.; Liu, X.; Ma, C.; Yang, J.; Yang, W.; Li, H. The Adsorption and Activation of Oxygen Molecular on Nickel Clusters Doped Graphene-Based Support by DFT. Mol. Catal. 2019, 477, 110547.

(44) Tang, Y.; Chen, W.; Li, C.; Li, W.; Dai, X. Geometric Stability, Electronic Structure, and Intercalation Mechanism of Co Adatom Anchors on Graphene Sheets. J. Phys. Condens. Matter 2015, 27, 255009.

(45) Krishnan, R.; Wu, S.-Y.; Chen, H.-T. Catalytic CO Oxidation on B-Doped and BN Co-Doped Penta-Graphene: A Computational Study. Phys. Chem. Chem. Phys. 2018, 20, 26414-26421.

(46) Martinez, U.; Komini Babu, S.; Holby, E. F.; Chung, H. T.; Yin, X.; Zelenay, P. Progress in the Development of Fe-Based PGM-Free Electrocatalysts for the Oxygen Reduction Reaction. Adv. Mater. 2019, 31, 1806545.

(47) Kwak, D.; Khetan, A.; Noh, S.; Pitsch, H.; Han, B. First Principles Study of Morphology, Doping Level, and Water Solvation Effects on the Catalytic Mechanism of Nitrogen-Doped Graphene in the Oxygen Reduction Reaction. Chem CatChem 2014, 6, 2662-2670.

(48) Matsuyama, H.; Akaishi, A.; Nakamura, J. Effect of Water on the Manifestation of the Reaction Selectivity of Nitrogen-Doped Graphene Nanoclusters toward Oxygen Reduction Reaction. ACS Omega 2019, 4, 3832-3838.

(49) Reda, M.; Hansen, H. A.; Vegge, T. DFT Study of Stabilization Effects on N-Doped Graphene for ORR Catalysis. Catal. Today 2018, $312,118-125$.

(50) Jung, E.; Shin, H.; Lee, B.-H.; Efremov, V.; Lee, S.; Lee, H. S.; Kim, J.; Hooch Antink, W.; Park, S.; Lee, K.-S.; et al. Atomic-Level Tuning of Co-N-C Catalyst for High-Performance Electrochemical H2O2 Production. Nat. Mater. 2020, 19, 436-442.

(51) Yang, M.; Wang, L.; Li, M.; Hou, T.; Li, Y. Structural Stability and $\mathrm{O} 2$ Dissociation on Nitrogen-Doped Graphene with Transition Metal Atoms Embedded: A First-Principles Study. AIP Adv. 2015, 5, 067136.

(52) Zhang, H.; Hwang, S.; Wang, M.; Feng, Z.; Karakalos, S.; Luo, L.; Qiao, Z.; Xie, X.; Wang, C.; Su, D.; et al. Single Atomic Iron Catalysts for Oxygen Reduction in Acidic Media: Particle Size Control and Thermal Activation. J. Am. Chem. Soc. 2017, 139, 14143-14149.

(53) Tai, S.-H.; Chang, B. K. Effect of Nitrogen-Doping Configuration in Graphene on the Oxygen Reduction Reaction. RSC Adv. 2019, 9, 6035-6041.

(54) Arrigo, R.; Schuster, M. E.; Xie, Z.; Yi, Y.; Wowsnick, G.; Sun, L. L.; Hermann, K. E.; Friedrich, M.; Kast, P.; Hävecker, M.; et al. Nature of the N-Pd Interaction in Nitrogen-Doped Carbon Nanotube Catalysts. ACS Catal. 2015, 5, 2740-2753.

(55) Chai, J.-D.; Head-Gordon, M. Long-Range Corrected Hybrid Density Functionals with Damped Atom-Atom Dispersion Corrections. Phys. Chem. Chem. Phys. 2008, 10, 6615-6620.

(56) Matanovic, I.; Artyushkova, K.; Strand, M. B.; Dzara, M. J.; Pylypenko, S.; Atanassov, P. Core Level Shifts of Hydrogenated Pyridinic and Pyrrolic Nitrogen in the Nitrogen-Containing Graphene-Based Electrocatalysts: In-Plane vs Edge Defects. J. Phys. Chem. C 2016, 120, 29225-29232.

(57) Freysoldt, C.; Grabowski, B.; Hickel, T.; Neugebauer, J.; Kresse, G.; Janotti, A.; Van De Walle, C. G. First-Principles
Calculations for Point Defects in Solids. Rev. Mod. Phys. 2014, 86, 253-305.

(58) Kumagai, Y.; Oba, F. Electrostatics-Based Finite-Size Corrections for First-Principles Point Defect Calculations. Phys. Rev. B: Condens. Matter Mater. Phys. 2014, 89, 195205.

(59) Broberg, D.; Medasani, B.; Zimmermann, N. E. R.; Yu, G.; Canning, A.; Haranczyk, M.; Asta, M.; Hautier, G. PyCDT: A Python Toolkit for Modeling Point Defects in Semiconductors and Insulators. Comput. Phys. Commun. 2018, 226, 165-179.

(60) Calle-Vallejo, F.; Martínez, J. I.; Rossmeisl, J. Density Functional Studies of Functionalized Graphitic Materials with Late Transition Metals for Oxygen Reduction Reactions. Phys. Chem. Chem. Phys. 2011, 13, 15639-15643.

(61) Chaban, V. V.; Prezhdo, O. V. Nitrogen-Nitrogen Bonds Undermine Stability of N-Doped Graphene. J. Am. Chem. Soc. 2015, 137, 11688-11694.

(62) Noffke, B. W.; Li, Q.; Raghavachari, K.; Li, L.-s. A Model for the PH-Dependent Selectivity of the Oxygen Reduction Reaction Electrocatalyzed by N-Doped Graphitic Carbon. J. Am. Chem. Soc. 2016, 138, 13923-13929.

(63) Zhang, L.; Niu, J.; Dai, L.; Xia, Z. Effect of Microstructure of Nitrogen-Doped Graphene on Oxygen Reduction Activity in Fuel Cells. Langmuir 2012, 28, 7542-7550.

(64) Nakada, K.; Ishii, A. Migration of Adatom Adsorption on Graphene Using DFT Calculation. Solid State Commun. 2011, 151, $13-16$.

(65) Li, Y.; Zhou, Z.; Shen, P.; Chen, Z. Spin Gapless Semiconductor-Metal-Half-Metal Properties in Nitrogen-Doped Zigzag Graphene Nanoribbons. ACS Nano 2009, 3, 1952-1958.

(66) Frisch, M. J.; Trucks, G. W.; Schlegel, H. B.; Scuseria, G. E.; Robb, M. A.; Cheeseman, J. R.; Scalmani, G.; Barone, V.; Mennucci, B.; Petersson, G. A.; Nakatsuji, H.; Caricato, M.; Li, X.; Hratchian, H. P.; Izmaylov, A. F.; Bloino, J.; Zheng, G.; Sonnenberg, J. L.; Hada, M.; Ehara, M.; Toyota, K.; Fukuda, R.; Hasegawa, J.; Ishida, M.; Nakajima, T.; Honda, Y.; Kitao, O.; Nakai, H.; Vreven, T.; Montgomery, J. A., Jr.; Peralta, J. E.; Ogliaro, F.; Bearpark, M.; Heyd, J. J.; Brothers, E.; Kudin, K. N.; Staroverov, V. N.; Keith, T.; Kobayashi, R.; Normand, J. N.; Raghavachari, K.; Rendell, A.; Burant, J. C.; Iyengar, S. S.; Tomasi, J.; Cossi, M.; Rega, N.; Millam, J. M.; Klene, M.; Knox, J. E.; Cross, J. B.; et al. Gaussian 09; Gaussian, Inc.: Wallingford CT, 2010.

(67) Groves, M. N.; Chan, A. S. W.; Malardier-Jugroot, C.; Jugroot, M. Improving Platinum Catalyst Binding Energy to Graphene through Nitrogen Doping. Chem. Phys. Lett. 2009, 481, 214-219.

(68) Owens, F. J. Electronic and Magnetic Properties of Armchair and Zigzag Graphene Nanoribbons. J. Chem. Phys. 2008, 128, 194701.

(69) Jiao, Y.; Zheng, Y.; Jaroniec, M.; Qiao, S. Z. Origin of the Electrocatalytic Oxygen Reduction Activity of Graphene-Based Catalysts: A Roadmap to Achieve the Best Performance. J. Am. Chem. Soc. 2014, 136, 4394-4403.

(70) Becke, A. D. Density-functional thermochemistry. III. The role of exact exchange. J. Chem. Phys. 1993, 98, 5648-5652.

(71) Lee, C.; Yang, W.; Parr, R. G. Development of the ColleSalvetti Correlation-Energy Formula into a Functional of the Electron Density. Phys. Rev. B 1988, 37, 785-789.

(72) Perdew, J. P.; Burke, K.; Ernzerhof, M. Generalized Gradient Approximation Made Simple. Phys. Rev. Lett. 1996, 77, 3865-3868.

(73) Heyd, J.; Scuseria, G. E.; Ernzerhof, M. Hybrid Functionals Based on a Screened Coulomb Potential. J. Chem. Phys. 2003, 118, $8207-8215$

(74) Garza, A. J.; Scuseria, G. E. Predicting Band Gaps with Hybrid Density Functionals. J. Phys. Chem. Lett. 2016, 7, 4165-4170.

(75) Frisch, M. J.; Trucks, G. W.; Schlegel, H. B.; Scuseria, G. E.; Robb, M. A.; Cheeseman, J. R.; Scalmani, G.; Barone, V.; Petersson, G. A.; Nakatsuji, H.; Li, X.; Caricato, M.; Marenich, A. V.; Bloino, J.; Janesko, B. G.; Gomperts, R.; Mennucci, B.; Hratchian, H. P.; Ortiz, J. V.; Fox, D. J. Gaussian 16. Gaussian, Inc.: Wallingford CT 2016.

(76) Glendening, E. D.; Reed, A. E.; Carpenter, J. E.; Weinhold, F. Gaussian09, NBO Version 3.1; Gaussian Inc., 2003. 
(77) Giannozzi, P.; Andreussi, O.; Brumme, T.; Bunau, O.; Buongiorno Nardelli, M.; Calandra, M.; Car, R.; Cavazzoni, C.; Ceresoli, D.; Cococcioni, M.; Colonna, N.; Carnimeo, I.; Dal Corso, A.; de Gironcoli, S.; Delugas, P.; DiStasio, R. A., Jr; Ferretti, A.; Floris, A.; Fratesi, G.; Fugallo, G.; Gebauer, R.; Baroni, S. Advanced capabilities for materials modelling with Quantum ESPRESSO. J. Phys.: Condens. Matter 2017, 29, 465901.

(78) Giannozzi, P.; Baroni, S.; Bonini, N.; Calandra, M.; Car, R.; Cavazzoni, C.; Ceresoli, D.; Chiarotti, G. L.; Cococcioni, M.; Dabo, I.; Dal Corso, A.; Fabris, S.; Fratesi, G.; de Gironcoli, S.; Gebauer, R.; Gerstmann, U.; Gougoussis, C.; Kokalj, A.; Lazzeri, M.; Martin-Sa, L.; Wentzcovitch, R. M. Quantum Espresso. J. Phys.: Condens. Matter 2009, 21, 395502.

(79) Prandini, G.; Marrazzo, A.; Castelli, I. E.; Marzari, N. M. Precision and efficiency in solid-state pseudopotential calculations. $n p j$ Comput. Mater. 2018, 4, 72.

(80) Lejaeghere, K.; Bihlmayer, G.; Björkman, T.; Blaha, P.; Blügel, S.; Blum, V.; Caliste, D.; Castelli, I. E.; Clark, S. J.; Dal Corso, A.; et al. Reproducibility in Density Functional Theory Calculations of Solids. Science 2016, 351, aad3000.

(81) Zhou, Y.; Neyerlin, K.; Olson, T. S.; Pylypenko, S.; Bult, J.; Dinh, H. N.; Gennett, T.; Shao, Z.; O’Hayre, R. Enhancement of Pt and Pt-Alloy Fuel Cell Catalyst Activity and Durability via NitrogenModified Carbon Supports. Energy Environ. Sci. 2010, 3, 1437-1446.

(82) Pyykko, P.; Desclaux, J. P. Relativity and the Periodic System of Elements. Acc. Chem. Res. 1979, 12, 276-281. 